\title{
3D non-linear behavior of masonry arch bridges
}

\author{
by \\ Gabriele MILANI $^{*}(1)$, Paulo B. LOURENÇO ${ }^{(2)}$ \\ (1) Department of Structural Engineering (DIS), Technical University in Milan, Piazza \\ Leonardo da Vinci 32, 20133 Milan, Italy \\ (2) Department of Civil Engineering, University of Minho, Campus de Azurem, Guimaraes, \\ Portugal \\ *Corresponding author. E-mail: milani@stru.polimi.it. \\ Phone: +39022399 4290 Fax: +39022399 4220
}

\begin{abstract}
In this paper, the static non-linear behavior of masonry bridges is numerically analyzed by means of a 3D FE numerical code. In particular, the three dimensional behavior of the structures when subjected to eccentric loads, the actual 3D geometry of the bridges (particularly important when skew arches are analyzed) and the strengthening effect induced by the backfill are considered.

The code is non-commercial and is applied here for the first time in presence of a very large number of elements and different materials. It relies in a FE discretization of the structure by means of rigid infinitely resistant eight-noded parallelepiped elements and non-linear interfaces, exhibiting deterioration of the mechanical properties. Each material of the bridge (arch, buttresses, piers, fill) is suitably modeled using interfaces having different constitutive behavior and mechanical properties.

Two real scale masonry bridges are analyzed, namely a skew single span structure experimentally tested up to failure at the Bolton Institute, UK and a straight multi span bridge constituted by 5 circular arches and loaded with an eccentric load. Both 2D and 3D limit analyses are also performed to have full insight into the actual capabilities of the 3D approach to reproduce peak loads and deformed shapes at failure and, at the same time, to investigate limitations of 2D hypotheses when transversal effects induced by geometry and load eccentricity are not considered.
\end{abstract}

Keywords: masonry bridges, non-linear static analysis, 3D FE model, transversal effects, arch-fill interaction 


\section{Introduction}

Masonry bridges date back over 4000 years. Many of those bridges, which were originally built for the passage of carts, are being used for road and rail vehicles. They demonstrate a surprisingly high load bearing capacity and good durability, see e.g. [1]-[3]. For these reasons, several ancient arch bridges are still in use today, even if the most part is relatively recent (19th century). Still, with time, masonry bridges have deteriorated and the safety requirements changed. The axle loads, number of axles and the vehicle speed the bridges are subjected to, have changed significantly in the past century. As a rule, the owners of these structures often consider them prohibitively difficult to rate, and establish ratings based on rules of thumb. For this reason, there is still a need for novel arch bridge assessment tools.

At present, a large amount of literature regarding the analysis up to collapse of masonry arch bridges and masonry arches in general is present [4]-[9]. However, such literature focuses almost exclusively on 1D/2D problems. Obviously, such structural models involve varying levels of accuracy and simplifications, which limit their range of applicability to specific cases. The most common idealizations of masonry material behavior are elastic, plastic and nonlinear (for a detailed discussion the reader is referred to e.g. [10]), but the most diffused theoretical approach, particularly in the case of masonry arch bridges, still remains limit analysis [2][3][7][11]. Limit analysis provides very quickly failure mechanisms and an estimation of the load carrying capacity of the structure. Besides the historic rules [14], the classic approach to determine the stability of arch bridges is probably due to Pippard \& Ashby [15] and Pippard [4]. This starts from a two-hinge arch for which the minimum load applied to a fixed position is determined, so that the arch turns into a mechanism constituted by four hinges. The exact positions of the two plastic hinges are variables to be determined. This approach was further extended by Heyman [12] introducing thrust-lines. The procedure may be handled without computational assistance, and fits well with experimental data for very simple arches without backfill and under specific loading conditions. More recent works (e.g. Gilbert and Melbourn [5], Hughes and Blackler [16] and Boothby [6]) are based on a rigid block discretization of the arches within limit analysis concepts coupled with FEs. While such an approach is very appealing because it provides failure mechanisms and load multipliers for a variety of different 2D geometries and loading conditions, still it is based on strong simplifications, which disregard 3D effects and consider the role played by the backfill only in an approximate way.

To rigorously investigate the role played by the backfill in the determination of the actual load carrying capacity of 2D bridges, a discretization with plane strain rigid-plastic elements and interfaces is needed, as recently proposed by Cavicchi and Gambarotta [2][3]. While this latter 
approach is very powerful, giving good predictions of the actual behavior of real bridges, it still has the disadvantage that it cannot be used for the analysis of skewed arches. Transversal effects may be very important from a practical point of view, playing a crucial role in the decrease of the load bearing capacity and 3D limit analyses models seem still missing in the technical literature, essentially because of the prohibitive computational cost required by refined discretizations within linear programming. While limit analysis is a very appealing alternative to common non-linear simulations, it is unable to give any prediction of the pseudo-ductility of the structure, because of the material hypotheses at the base of such strategy (infinite ductility of the constituent materials). To have a prediction on displacements in the non-linear range, non-linear FE approaches (ranging from 1D up to full 3D) have thus been used in the past [9][17][18][19]. For complex geometries, FEs models are sometimes constituted by many elements and variables, making the solution of the incremental problem difficult even for small bridges, particularly in presence of softening behavior for the constituent materials, which is required for masonry. In addition, since commercial codes are normally used, it is also difficult to adapt material models available to the actual masonry behavior, to properly take into account the orthotropy along material axes, softening behavior and separate failure surfaces for tension and compression [20]-[24]. Finally, to arrive at a good match between real and predicted behavior such models require a large amount of input data.

From the above considerations, it appears clear that, in general, to properly take into account all the aspects influencing masonry bridges behavior, such as non-linearity of the materials, arch-fill interaction, transversal effects, actual geometry, etc., is not an easy task. For these reasons, in the present paper a novel full 3D non-linear FE model is proposed, to have a detailed insight into the three-dimensional behavior of arch bridges far from the elastic range. The code relies in a discretization of the 3D domain by means of rigid eight-noded elements interconnected by nonlinear interfaces. A simplified degradation law for masonry interfaces is assumed following a linear piecewise constant approximation, to properly take into account the softening behavior of the structure within a well-established Sequential Quadratic Programming scheme (see [25]). Mechanical properties of the non-linear interfaces are totally defined, and may be tuned at the meso-scale level to properly take into account, for instance, the orthotropic behavior of the spandrels or to model each single block of the arch. While the code has been already successfully utilized for the homogenized non-linear analysis of masonry curved structures, it is used for the first time in this paper to analyze 3D bridges with several different materials interacting with the backfill. Note also that the proposed approach overcomes the problems with the prediction of unrealistically low collapse loads indicated in [26] and requiring a special load-path following solutions procedure. 
Two different case studies are analyzed in the paper to fully assess numerical results. The first example is a single span skew bridge experimentally tested at the Bolton Institute, UK [27]-[29]. Comparisons with standard elasto-plastic FEM, a commercial limit analysis FE software (Ring 1.5 [30]), non-commercial 2D [31] and 3D [23] FE limit analysis codes are also provided to evaluate (1) the influence of the backfill on the carrying capacity of the bridge and the (2) effect induced by the skewness. The second example addresses an existing multi-span bridge located in Southern Italy. Eccentric loads are applied to two spans up to failure in order to evaluate the ductility and load bearing capacity of the structure when subjected to eccentric loads, simulating the passage of a train. Suitable comparisons with standard FEM and 1D/2D limit analysis (Ring software [30] and non-commercial 2D/3D limit analysis [31] [23]) are again reported to stress the limitations of approaches with simplified geometries.

\section{The adopted numerical model}

A macro-scale approach is utilized in the paper. In particular, spandrels are modeled by means of an orthotropic homogenized material obtained with a mesoscopic approach similar to that proposed in [32], whereas filler is modeled by means of an isotropic Mohr-Coulomb material with tension cutoff and softening, as shown in Figure 1. The arch is modeled again by means of a macroscopic approach but respecting in the front view the actual disposition of the blocks, in order to have a more precise evaluation of the position of the plastic hinges forming the failure mechanism.

To solve the non-linear structural analysis problem, a sequential quadratic programming procedure with a discretization by means of eight-noded rigid elements and non-linear interfaces, Figure 2, similar to that proposed in [25][32] is adopted.

The following issues of the approach proposed are worth noting:

1. Bridge spandrels mechanical properties are obtained by means of the FE homogenization procedure schematically shown in Figure 3. Joints are reduced to interfaces and exhibit an elasto-plastic behavior with softening, Figure 1. The Representative Element of Volume (REV) is discretized by means of non-linear interfaces (joints) and elastic three-noded triangles (bricks). An estimation of the in-plane homogenized behavior to be used at a structural level is obtained suitably solving an incremental boundary value problem on the REV. The choice of a REV which geometrically represents correctly the actual disposition of the blocks (also along the thickness) is crucial for the numerical analyses reported hereafter. The superficial geometry of the structure under consideration may be mapped with very high accuracy by means of photogrammetric surveys, making use of the modern digital technology. When a very refined detail of the actual surface irregularities is needed, it 
is also possible to interface data acquired by means of laser scanner surveys to the structural code. However, for old masonry structures, the actual disposition of the blocks along the thickness remains unknown. In any case, for the cases under consideration, sections and planar views of the structures are directly available. In absence of such data, the matter persists and some destructive/non destructive experimental tests should be performed to have an estimation of the actual disposition of the blocks along the thickness.

2. At a structural level bridges are discretized by means of parallelepiped rigid elements and quadrilateral elasto-plastic with softening interfaces where all deformation occurs, Figure 2.

3. Each interface is supposed interconnected with adjoining elements by means of three nonlinear displacement and three non-linear rotational springs.

4. The non-linear uniaxial behavior of the displacement springs is deduced for spandrels by means of a FE homogenization, Figure 3 or directly using the constitutive behavior, Figure 1 , for the backfill and the mortar joints belonging to the arch, when it is chosen to adopt a heterogeneous approach to model the arch. Bending and torsional behavior are derived from displacement springs by means of a specific integration procedure recalled in detail in the following sub-section.

\subsection{Discretization with elastic continuum elements and non-linear interfaces}

The discretization is carried out through 3D rigid infinitely resistant eight-noded wedge elements interacting by quadrilateral non-linear interfaces exhibiting softening. Any shape of the parallelepiped element can be managed, i.e. also distorted meshes may be handled in the code, as commonly done in commercial software. Within such assumptions, all deformation (linear and nonlinear part) is concentrated exclusively at interfaces (modeled assuming either an isotropic frictional material, as for the backfill, or by means of a homogenized orthotropic material as in case of spandrels), thus requiring a small number of optimization variables to be performed.

Kinematic variables for each element are represented by three centroid displacements $\left(u_{x}^{E}, u_{y}^{E}, u_{z}^{E}\right)$ and three rotations around centroid $G\left(\Phi_{x}^{E}, \Phi_{y}^{E}, \Phi_{z}^{E}\right)$, see Figure 2. The $\Gamma_{12}^{E}$ edge surface of a wedge element $E$, connecting $P_{1}-P_{2}-P_{3}$ and $P_{4}$ nodes, results in a quadrilateral and the jump of displacements on it is linear.

The adopted finite element model relies into a discretization through parallelepiped elements, assumed rigid infinitely resistant, and quadrilateral interfaces where all deformation occurs (linear and non-linear). Each interface connects rigid elements representing the same homogenized materials. For each interface, three translational and three rotational non-linear springs are utilized, as schematically shown in Figure 2. To properly take into account some distinctive aspect of 
masonry behavior in flexure (dependence of the flexural behavior by in-plane compression), but limiting to a great extent the number of optimization variables involved in the quadratic programming (QP) scheme, see e.g. De Donato \& Franchi [33], the procedure envisaged in Figure 3 is adopted for each interface.

For each interface, depending on its orientation with respect to blocks disposition, the homogenized stress-strain behavior is known from the meso-scale. At each assumed strain $\varepsilon_{n}$, an interface displacement at the macro-scale is univocally associated simply applying what was stated in Kawai [34]. For the interface $k$ the homogenized stress-strain relationship is therefore known for each point of the interface. By integration with a reasonable subdivision along the thickness into layers (from the authors experience, 10 layers is a good compromise between numerical efficiency and accuracy) the compression load $N^{(i-1)}$ on the interface at the (i-1)-th iteration is known. At a fixed value of membrane normal force, the non-linear relationship moment-curvature is known again from the meso-scale, along with its linear stepwise constant approximation (necessary to use in the sequential quadratic programming scheme, as discussed below). Again, curvatures and rotations, necessary when a discrete representation at a structural level is adopted, can be trivially obtained according to Kawai [34]. In this way, bending moment and torsion may be evaluated step by step during the deformation process simply by integration.

A database of moment-curvature diagrams at different levels of normal stresses is always at disposal from meso-scale computations before any structural non-linear simulation. When normal membrane force is within the range inspected but does not match exactly values investigated, a linear interpolation law for the diagrams is used. In order to utilize sequentially the QP approach an approximation of the non-linear behavior through a linear piecewise constant function is used.

Following this procedure, the resultant mechanical model is thus composed by 6 elasto-plastic springs, Figure 2. Within each iteration, an elastic-perfectly plastic approximation for each spring is utilized, meaning that 12 plastic multipliers for each interface are needed (two for each spring, $\lambda^{+}$ and $\lambda^{-}$, corresponding to positive or negative kinematic variables). In this way, optimization variables entering into the QP problem are relatively small (12 plastic multipliers for each interface, 3 displacements and 3 rotations for each element). Generally the QP problems handled did not exceed 10,000 variables.

Within the FE model adopted, the problem at hand (rigid elements with elastic-plastic interfaces) reads [32]: 


$$
\left\{\begin{array}{c}
\min \left\{\frac{1}{2}\left[\left(\Delta \boldsymbol{\lambda}^{+}-\Delta \boldsymbol{\lambda}^{-}\right)^{T} \mathbf{K}_{e p}\left(\Delta \boldsymbol{\lambda}^{+}-\Delta \boldsymbol{\lambda}^{-}\right)+\Delta \mathbf{U}_{e l}^{T} \mathbf{K}_{e l} \Delta \mathbf{U}_{e l}\right]-\Delta \mathbf{F}^{T} \Delta \mathbf{U}_{e l}\right. \\
\text { subject to }: \Delta \boldsymbol{\lambda}^{+} \geq \mathbf{0} \Delta \boldsymbol{\lambda}^{-} \geq \mathbf{0}
\end{array}\right.
$$

Assuming that the structural model has $n_{\text {in }}$ interfaces and $n_{e l}$ elements, the symbols in this equation have the following meaning:

$1 \mathbf{K}_{e l}$ is a $6 n_{e l} \times 6 n_{e l}$ matrix, collecting elastic stiffness of each interface. The local elastic stiffness matrix of each interface is obviously diagonal, whereas the global stiffness matrix $\mathbf{K}_{e l}$ is generally not diagonal. It is worth remembering that elastic stiffness values are evaluated at the meso-scale, as discussed in the previous section.

2. $\Delta \lambda^{+}$and $\Delta \lambda^{-}$are two $12 n_{\text {in }}$ vectors of plastic multiplier increments, collecting plastic multiplier increment of each non-linear spring (e.g. flexure, shear, etc.).

3. $\mathbf{K}_{e p}$ is a $12 n_{\text {in }} \times 12 n_{\text {in }}$ matrix built from diagonal matrices of hardening moduli of the interfaces. Differently to the elastic stiffness matrix, the global matrix of hardening moduli of interfaces is diagonal. Let us remark that in QP, the existence and uniqueness of the solution is assured if $\mathbf{K}_{e p}$ is square matrix with principal minors $>0$. To circumvent numerical instabilities, a small but nonzero hardening has to be introduced in order to avoid lack of convergence of the QP algorithm. Within a multistage loading approach, i.e. where the external load is incremented step by step, it may however occur that there is again lack of convergence of the QP algorithm, especially near the formation of a failure mechanism. A bisectional approach of the load increment is therefore utilized to avoid lack of convergence.

4. $\Delta \mathbf{U}_{e l}$ is a $6 n_{e l}$ vector collecting the displacement and rotation increments of the elements.

5. $\Delta \mathbf{F}$ is a $6 n_{e l}$ vector of external loads (forces and moments) increments applied on element centroids.

Typically, the independent variable vector is represented by element displacement increments $\Delta \mathbf{U}_{e l}$ and plastic multiplier vector increments $\Delta \lambda^{+}$and $\Delta \lambda^{-}$.

As usually done in a non-linear structural analysis, QP problem is solved in terms of displacement and plastic multipliers step increments. The initial solution of the problem is always represented by the solution at the previous step. Finally it is worth noting that the format of ( 1 ) essentially refers to a standard associated plasticity problem, compatible with the frozen-degradation modeling implemented within the iterative strategy proposed. While this assumption could at a first glance appear to be incompatible with the assumption of a non-associated flow-rule for mortar, it should be 
noted that, since interfaces are modeled at structural level through displacement and rotational springs, uniaxial behavior holds and the flow rule is associated by definition.

Within the model, the non-linear behavior of the springs is approximated using a lineardiscontinuous piecewise constant function, as depicted in Figure 5, where the stress-strain behaviors in horizontal compression and tension of the masonry material of Table I are represented. The physical meaning of symbols used in Table I are fully explained in Figure 1.

The drop of the load bearing capacity of the interfaces at increasing deformation is considered at a structural level within a sequential scheme which formally is identical to that proposed in [32]. The only difference is that here parallelepiped elements are used instead of wedge-shaped elements, whereas interfaces (where all inelastic deformation occurs) remain quadrilateral. A detailed description of the Sequential Quadratic Programming (SQP) scheme adopted is provided in [32] and is not repeated here for the sake of conciseness. Here it is worth noting only that the trial-anderror step-length sizing strategy above discussed is generally quite efficient but may become particularly tedious in presence of models with many interfaces and/or when the linear piecewise constant approximation assumed for the interface springs is very refined. This is obviously an intrinsic limitation of the procedure proposed and cannot be eliminated. For these reasons, crude approximations of the non-linear behavior of the springs are used.

Finally, it is interesting to notice that a theoretical limitation of the approach proposed is to assume that block kinematics must remain small. However, in recent literature it has been shown both experimentally and numerically that second order effects may have perceivable effects (reduction of the failure load and softening post-peak behaviour) only for slender panels. As consequence, typically, walls affected by buckling have slenderness, intended as the ration between height and thickness, greater than 30 , which is not the case of the masonry bridges considered in the paper.

\section{Possibilities of the FE model proposed}

In order to preliminary discuss some features of the non-linear FE code proposed to model masonry arches behaviour in the non-linear range, the semi-circular arch depicted in Figure 4-a is considered as benchmark. Such structure has been already analyzed in detail by Orduna (2005) by means of both a limit analysis approach with non-associated plasticity and by means of standard commercial FEM. The arch is constituted by 30 large stone blocks of dimensions $30 \times 10 \mathrm{~cm}^{2}$ and dry joints. It is interesting to notice that, while from a theoretical point of view, an unilateral contact problem may be not rigorously handled within the modeling strategy adopted in the paper, it is however possible from a practical point of view to tackle such kind of problem with sufficiently accuracy, simply 
assuming for dry joint interfaces a small but non-zero tensile strength, which well approximates a material unable to withstand tensile stresses, eventually exhibiting a friction behaviour.

The arch under consideration has a span $S$ equal to 5 meters, a rise $R$ equal to $2.5 \mathrm{~m}$, is $30 \mathrm{~cm}$ thick and 1 meter wide. Assuming that the arch is subjected to a permanent load $p$ not dependent on the load multiplier equal to $35 \mathrm{kN} / \mathrm{m}^{3}$, a concentrated point load $\lambda$ increased up to failure is applied at quarter span. To model the arch, a heterogeneous approach with rigid and infinitely resistant blocks meshed with parallelepiped elements is adopted.

Mechanical properties assumed in the numerical simulations for dry joints are kept in agreement with Orduna [35] indications, and are the following: $K_{n}=2400 \mathrm{~N} / \mathrm{mm}^{3}$ (normal stiffness of the mortar interface), $K_{n}=1000 \mathrm{~N} / \mathrm{mm}^{3}$ (tangential stiffness of the interface), $\tan \Phi=0.75$ (tangent of the friction angle for mortar), infinite blocks compressive strength.

Results of the non-linear FE analysis are schematically summarized in Figure 4 from -b to -c. In particular in Figure 4 -c a comparison among force-vertical displacement curve obtained by means of the model proposed, that provided by Orduna through a commercial code and limit analysis collapse loads (2D and 3D approaches by Milani et al.[31] [23] and non-associated approach with rigid blocks by Orduna[35]) is summarized. The displacement considered is the vertical translation of the centroid of the block positioned under the external point load $\lambda$. As it is possible to notice, the agreement regarding collapse loads is almost perfect, but also the displacements provided by the present numerical approach appear in very good agreement with existing code predictions. Figure 4c shows the deformed shape associated to the formation of the failure mechanism. It is particularly evident the formation of a four-hinge mechanism, with positions of the hinges almost superimposable to those provided by Orduna. In addition, it is interesting to notice that the unilateral contact behavior of joints to interfaces with infinite compressive strength seems to be reproduce quite accurately by the model, as can be seen both by the detail of the deformed shape in correspondence of the plastic hinges and the deterioration patch of the interfaces depicted in Figure 4-d. Finally, it should be underlined that, while 2D and 3D limit analysis approaches by Milani et al.[31] [23] assume an associated plasticity law for joints, differently to the non associated approach [35], here the result is identical because the failure mechanism is constituted by plastic hinges with joints working in bending.

\section{The case studies considered}

The first structure studied is a skew arch experimentally tested by Melbourne \& Hodgson [28], whereas the second is a five-ring existing railway arch bridge, located in the south Italy. For the first bridge, a vertical eccentric load is applied up to collapse and the behavior of the bridge is 
evaluated by means of the non-linear FE model proposed. The behavior of the same arch without skewness and again studied by Melbourne \& co-workers [27]-[29] is also discussed to evaluate the influence of geometric asymmetry on the load bearing capacity of masonry bridges. When dealing with the second example, eccentric loads simulating the passage of a train are investigated. In order to have a deep insight into the non-linear behavior of the structures, loads are increased up to collapse of the bridges. This approach allows to numerically estimate crack pattern, failure mechanism, ultimate load bearing capacity of the structure as well as to have an insight into the overall ductility and local deformation.

For all the cases analyzed, comparisons with 2D and 3D limit analysis simulations performed using codes implemented by the authors [23][31] and commercial Ring 1.5 software [30] are also provided, which allow estimating (1) how sensitive the bridges are to asymmetries of geometry and loads and (2) what is the increase of the load bearing capacity provided by the backfill.

\subsection{Bolton Institute arch bridges loaded up to collapse}

Two masonry bridges were experimentally tested at Bolton Institute [27]-[29], including straight and skewed arches, with identical geometry, in order to evaluate geometry asymmetry influence on the non-linear behavior of masonry bridges. The geometrical properties of the bridges here numerically analyzed are depicted in Figure 6. In each test, up to 300 gauges were installed by Melbourne and co-workers [27]-[29], including vibrating wire strain gauges and deflection gauges, having in mind to collect a huge amount of experimental information useful for an evaluation of the final deformed shape. Soil pressure cells were also installed in the backfill to monitor backfillstructure interaction and backfill pressure distribution.

The nominal square span of the arch barrel is $3 \mathrm{~m}$ and the rise of the crown $0.75 \mathrm{~m}$. The profile is segmental (perpendicular to the abutments) with a radius equal to $1.875 \mathrm{~m}$. Dimensions of straight and skew bridges were chosen identical to facilitate comparisons on peak loads and deformed shapes at failure. When dealing with skew arches, the nominal skew of the arches is $45^{\circ}$. The mean thickness of the barrel is $0.22 \mathrm{~m}$ and comprises two rings of Class A Engineering bricks, laid helicoidally in running bond. There are no headers between the rings, hence any composite action is solely a result of the mortar bond. Each bridge was subjected to a vertical linear load up to collapse positioned as indicated in Figure 6.

Melbourne et al. [27]-[29] experimentally determined the mortar compression strength, which was found to range between 1.8 and 2.3 $\mathrm{MPa}$. Shear tests were also conducted on mortar, indicating a shear resistance ranging between 0.28 and $0.34 \mathrm{MPa}$. Brickwork prisms were tested in compression, indicating a compressive strength equal to $28 \mathrm{MPa}$, initial tangent modulus equal to $18000 \mathrm{MPa}$ and 
a Poisson's ratio equal to 0.16 . A $50 \mathrm{~mm}$ graded limestone rubble with an internal friction angle of $59.5^{\circ}$, zero cohesion and a bulk density of $2265 \mathrm{Kg} / \mathrm{m}^{3}$ was used for the backfill of the arches.

Mechanical properties assumed for masonry and backfill in the model are summarized in Table I and, where possible, are in agreement with experimental data provided by Melbourne and coworkers [27]-[29]. Missing data, especially in the inelastic range, have been assumed in agreement with internationally recognized literature. The elastic and inelastic behavior of interfaces in uniaxial tension-compression and pure shear within the model (backfill, spandrels and arch) are depicted in Figure 5. For the backfill, a Mohr-Coulomb failure criterion with tension cutoff was used, in agreement with Cavicchi \& Gambarotta [2][3]. A quite marked softening behavior is assumed in tension, to reproduce a typical brittle behavior. Post-peak behavior in shear exhibits again softening, even if decreasing with increasing vertical pre-compression. For the spandrels a homogenized masonry material exhibiting an orthotropic behavior along material axes with softening was used. Since spandrels are built in English Bond texture, their macroscopic behavior was derived by means of the compatible model by Cecchi and Milani [36] and the non-linear approach proposed in Milani \& Tralli [32]. When dealing with the barrel vault, here it is worth noting that blocks are disposed on a double row to for the entire arch thickness, and helicoidally in running bond along the width of the bridge. While the discretization of each single block in the model would lead to unpractical refined discretizations, the actual disposition of the blocks is respected in the spandrels plane, whereas along bridge width it is lost at a structural level. It is however expected that the global behavior of the structure is kept using this simplification. The uniaxial and shear behavior of the barrel vault is again depicted in Figure 5 and obviously coincides with mortar stress-strain curves, being interfaces between blocks actually coincident with blocks. Abutments are finally assumed infinitely resistant in the model. The FE discretization utilized for both the right and the skew arch are represented in Figure 7.

From full scale experimentation conducted by Melbourne et al. [27]-[29], the following observations on the mechanical behavior of the structures were made:

- The straight arch failed at around $600 \mathrm{kN}$ of external load, whereas the change in geometry enabled the skew arch to form a mechanism at a much smaller load of $372 \mathrm{kN}$, see Figure 8.

- In the straight arch, the barrel vault failed with the formation of a four hinge mechanism, with cylindrical hinges parallel to abutments, Figure 9.

- The stiffness of the arch is increased by skewness, see Figure 8 and Figure 9. The inward radial deflections beneath the load were similar between straight and skew arch, however the outward deflections were much smaller and limited to a comparatively small region near the west corner, Figure 9. 
- The effect of the skew was noticeable in the hinge pattern within the east spandrel wall, which was much different from the hinge pattern within the west spandrel wall. Skew created the necessity for the formation of a five hinge mechanism in which each in-span hinge was inclined with respect to all three global orthogonal axes.

Load displacement curves obtained with the model proposed are represented in Figure 8, whereas in Figure 9 deformed shapes at peak are represented. In Figure 8, several additional numerical results are also represented. In particular three different limit analysis models are utilized to predict the actual load carrying capacity of the bridges. The first model relies into the commercial Ring 1.5 software [30]. Ring 1.5 works with 2D geometries and considers backfill interaction only in an approximate way, utilizing some elastic formulas originally proposed for soils. It is therefore expected that such approach provides failure loads independent from bridges transversal geometry and are not very sensitive to the role played by the backfill. To circumvent this latter drawback, a full 2D upper bound limit analysis code developed by the authors and similar to that proposed by Cavicchi and Gambarotta [2][3] is also utilized. It relies into a 2D plane-strain discretization of the domain by means of several different materials, triangular elements with linear interpolation of the velocity field and frictional linear interfaces with linear jump of velocities, in agreement with the model originally presented by Sloan \& Kleeman [37]. While this latter approach correctly accounts for the increase of the load bearing capacity due to backfill presence, it again disregards 3D effect. As a matter of fact, the contemporary presence of both the backfill and the spandrel walls, may be rigorously accounted for only using a full 3D discretization. On the contrary, it is not possible to model both spandrels and backfill within a 2D approach, thus making the numerical problems discussed particularly suited to the application of 3D software. As a result, the presence of the backfill is a topic that deserves consideration here, not only for its stabilizing effect, but especially because it may increase the three-dimensional behaviour of the structure, hence potentially enlarging the differences between 2D and full 3D approaches in presence of skew geometries and/or eccentric loads.

For this reason, within a limit analysis assumption a further 3D limit analysis model is also used, consisting of a discretization of the bridge by means of rigid tetrahedron elements and rigid plastic triangular interfaces between adjoining elements, as proposed by Milani et al. in [38]. It is expected that, for sufficiently refined discretizations, this latter approach provides reliable evaluations of both the collapse loads and failure mechanisms, for both the skew and the straight arch.

A comparison with all limit analysis models above recalled, experimental data and present simulations results is reported in Figure 8-a, where load-maximum displacement curves provided by the present model are compared with failure loads obtained with limit analysis (Ring 1.5, 2D and 
3D upper bounds). In addition, force-displacement curves obtained using a standard elasto-plastic full 3D commercial finite element software (Strand 7.2 [39]) where materials are modeled as elastic-perfectly plastic with a Drucker-Prager failure criterion are represented.

As it is possible to notice, Ring 1.5 provides quite low failure loads, since the arch fill interaction is not properly taken into account, even if the deformed shape at failure of the barrel vault, Figure 8-b, is in very good agreement with experimental evidence and alternative numerical approaches. The reason of this mismatching stands probably in the modeling of the arch fill interaction, which assumed a load dispersion through the fill according to the classical Boussinesq distribution with a dispersion angle of $30^{\circ}$, while an earth pressure coefficient $k_{p}$, based on the Rankine theory and equal to half of the value adopted for arches. In addition, the presence of a double row of blocks in the arches further decreases the failure load, with a very detailed description of the actual position of the plastic hinges. When a single row of blocks is used, failure load increases, as expected, up to $650 \mathrm{kN}$. 2D limit analysis seems to fit better experimental failure loads found in case of the straight arch. In Figure 8-c the deformed shape at failure (with normalized plastic dissipation patch) provided by the 2D model is represented. The deformed shape of the barrel vault is very similar to that provided by Ring software. However, the interaction of the fill is here very clear, with an evident contribution of the internal dissipation of the backfill, especially under the point of application of the load and in the left upper part of the bridge. Finally 3D limit analysis provides very good results both in the straight and skew arch case, because of the possibility to model the actual geometry and the backfill interaction properly. Here it is worth noting that, while in the 2D upper bound limit analysis model spandrels may not be modeled, in the 3D discretization both spandrels and backfill are present. This justifies the extra resistance exhibited by the 3D model when compared to the $2 \mathrm{D}$ approach.

In Figure 9 deformed shapes at peak provided by the present non-linear model in the case of the straight and skew arch are compared with vertical displacement patches obtained experimentally. In Figure 10 deformed shapes at peak obtained numerically for the barrel vault are represented from different point of views for both arches. The failure mechanism for the skew arch is rather complex to interpret and again in general agreement with experimental evidences. From the deterioration patches of the interfaces due to normal and tangential stresses shown from Figure 11 to Figure 14, it is pretty clear that flexural hinges in the skew arch are less marked than in the straight arch and always mixed with diffused zones exhibiting punching, especially under the external loads, between spandrels. The deformed shapes obtained numerically for spandrels walls are compared with experimental evidence in Figure 15. Good agreement is found between model and experimental data. In particular, it can be seen that spandrel walls were very much involved in the failure 
mechanism. A system of hinge-like cracks is visible in the numerical model in both spandrels and extensive ring separation is also visible.

\subsection{Ancient multi-span railways arch bridge}

The behavior of the five span right railway arch bridge represented in Figure 16 and subjected to vertical eccentric loads is studied as second example. The bridge is an existing structure located in the Southern Italy. The width of the structure is equal to $7.10 \mathrm{~m}$ and permits the passage of a double track. Each arch, having a span equal to approximately 10 meters is supported by four piers with cross section equal to $2.40 \mathrm{~m} \times 7.10 \mathrm{~m}$ (length $\times$ width), the central piers having considerable height (about 15 meters) and two squat lateral abutments. Piers external surfaces and spandrels are constituted by relatively large sandstones with almost regular parallelepiped shape and approximate dimensions equal to $50 \times 35 \times 35 \mathrm{~cm}$. Piers core is filled by gravels and mortar with quite poor mechanical properties. Circular holes are present immediately above the head of the piers, traditionally conceived in masonry bridges to favor water outflow in case of floods.

Backfill is constituted by quasi incoherent material, as in the previous case studied. Mechanical properties assumed in the simulations for the constituent materials are summarized in Table II.

A medium refined discretization is utilized for the numerical analysis of the bridge, as shown in Figure 16. The mesh is constituted by 4872 elements, 7791 nodes and 11992 quadrilateral interfaces, with four elements disposed along the bridge thickness, to properly reproduce out-ofplane bending when the structure is subjected to eccentric loads.

Apart self-weight, the bridge is supposed loaded by two vertical distributed pressures simulating two electric locomotives placed in correspondence of the second and fourth arch, both on the same track, in agreement to one load combination recommended by regional Italian railways internal codes. In order to have an insight into the non-linear behavior of the structure under increasing vertical eccentric actions, both loads are incremented up to failure of the structure. These simulations provide interesting information on failure mechanisms active, with a possible evaluation of the importance of out-of-plane effects.

Load displacement curves obtained with the numerical model proposed are depicted in Figure 17, where results provided by limit analysis (both 2D and 3D models), Ring 1.5 software and an alternative isotropic elasto-plastic approach conducted within the commercial code Strand 7 are represented. In this latter case, materials are modeled by means of a Drucker-Prager failure criterion with the same cohesion and friction angle utilized in the non-linear model proposed, see Table II.

As it is possible to notice, there is a difference of around $10 \%$ between failure loads provided by the 2D and 3D limit analyses, meaning that 3D effects are, for right arches with asymmetric loads along the thickness, less marked if compared to skew arches response, but still meaningful from an 
engineering point of view. Peak loads are associated to an evident global mode of the structure, with instability of the long piers, which is reproduced both by the 3D limit analysis code and the incremental non-linear model, as can be noticed by the deformed shape at peak represented in Figure 18.

From normalized plastic dissipation patches referred to normal and shear actions and represented in Figure 19 and Figure 20 respectively, the formation of plastic hinges in arches belonging to the second and fourth span can be clearly noted, both at the intrados and extrados, with a predominant damage in the second span. This is not surprising, because piers are here much more slender and the lateral constraint of the arch is much less effective, as also shown well by the deformed shape reported in Figure 18. Differently to the Bolton right arch bridge, where plastic hinges - which are referred to the deterioration of normal stress- are well defined and may be approximated with lines, here damage diffuses a little bit laterally. The fact that this type of plasticization spreads may be explained with the relatively small amount of backfill present, which makes the overall behavior of the bridge more monolithic.

The eccentricity of the loads makes the plasticization patch again quite visibly unsymmetrical, with a concentration on the extrados elements in the mid-span of the loaded arches, under the loaded track.

The backfill has again a stabilizing role, but much less marked in this case, as expected since the total volume of the backfill is in percentage lower. In addition, the presence of the circular holes at the head of the piers does not allow a uniform redistribution of vertical stresses laterally in the backfill, thus decreasing further the increment of load bearing capacity obtainable with the backfill. It is therefore not surprising that Ring 1.5 predictions are in good agreement with $2 \mathrm{D}$ limit analysis results, see Figure 17. 3D limit analysis collapse loads are a bit lower than 2D predictions, as theoretically expected, due both to the enriched kinematic of the numerical model and the possibility of the 3D mesh to deform plastically out-of-plane.

\section{Conclusions}

A simple but effective fully 3D numerical model for the analysis of masonry bridges interacting with the backfill has been presented. The model is non-linear and allows a fast evaluation of inelastic response of the bridges following also the descending branch, thanks to the discretization by means of parallelepiped elements interacting by means of non-linear displacement and rotational springs and the utilization of non-linear programming routines instead of classic incremental FEM. 
The code successfully converges in presence of relatively refined discretizations and materials with quite different mechanical properties, all exhibiting deterioration of the mechanical properties in shear, tension and compression.

When compared with existing -and more generalist- Distinct Element Codes (as UDEC) or the Applied Element Method AEM (as ELS), the software proposed seems more suited for the analysis of massive existing masonry arch bridges, because specifically conceived for handling such kind of structures. Furthermore, thanks to the preliminary homogenization procedure performed before structural analyses, a more precise characterization of the masonry material is possible at a structural level, with independent modeling of tension and compression behavior and possibility to account for masonry orthotropy in presence of different textures. Another improvement under study by the authors is the introduction of FRP strips, to have an insight into the structural efficiency of innovative strengthening interventions for massive masonry structures with poor mechanical properties.

Two real scale masonry bridges have been analyzed, namely a skew single span structure experimentally tested up to failure at the Bolton Institute, UK and a straight multi span bridge constituted by 5 circular arches and loaded with an eccentric load. To fully assess numerical results provided by the approach proposed, both 2D and 3D limit analyses have been also performed, in conjunction with elasto-plastic analyses conducted with commercial FEM. At the same time, the limitations of 2D hypotheses when transversal effects induced by geometry and load eccentricity are disregarded have been investigated. The results indicate a clear benefit of using 3D analysis of masonry arch bridges for the cases analyzed. Generally speaking, however, 3D modelling is needed only for skewed geometries and general 3D non symmetric loading conditions. 2D approaches still remain adequate in all other cases and a time consuming full 3D discretization may be avoided.

\section{References}

[1] Oliveira, D.V., Lourenço, P.B., Lemos, C., Geometric issues and ultimate load of masonry arch bridges from the northwest Iberian Peninsula, Engineering Structures, 32(12), p. 3955-3965 (2010).

[2] Cavicchi A, Gambarotta L (2005). Collapse analysis of masonry bridges taking into account archfill interaction. Engineering Structures 27(4): 605-615.

[3] Cavicchi A, Gambarotta L (2006). Two-dimensional finite element upper bound limit analysis of masonry bridges. Computers \& Structures 84(31-32): 2316-2328.

[4] Pippard AJS (1948). The approximate estimation of safe loads on masonry bridges, Civil engineer in war: Institution of Civil Engineers, 1, 365.

[5] Gilbert M, Melbourne C (1994). Rigid-block analysis to masonry arches, Structural Engineering, 72, 356-361.

[6] Boothby T (1995). Collapse modes of masonry arch bridges, Journal of the British masonry society, 9(2), 62-69.

[7] Gilbert M (2006). Limit analysis of masonry block structures with non-associative frictional joints using linear programming, Computers and Structures 84: 873-887. 
[8] de Felice G, De Santis S (2010). Experimental and Numerical Response of Arch Bridge Historic Masonry Under Eccentric Loading. International Journal of Architectural Heritage 4(2): 115-137.

[9] Audenaert A, Fanning P, Sobczak L, Peremans H (2008). 2-D analysis of arch bridges using an elasto-plastic material model. Engineering Structures, 30: 845-855.

[10] Lourenço PB, Milani G, Tralli A, Zucchini A (2007). Analysis of masonry structures: review of and recent trends in homogenisation techniques. Canadian Journal of Civil Engineering, 34 (11): 1443-1457.

[11] Drosopoulos GA, Stavroulakis GE, Massalas CV (2006). Limit analysis of a single span masonry bridge with unilateral frictional contact interfaces. Engineering Structures 28(13): 1864-1873.

[12] Heyman J (1969). The safety of masonry arches. International Journal of Mechanical Sciences 43: 209-224.

[13] Huerta S (2001). Mechanics of masonry vaults: the equilibrium approach. In: Proc. Historical Constructions, P.B. Lourenço \& P. Roca (Eds.), Guimarães PT.

[14] Brencich, A., Morbiducci, R. (2007). Masonry Arches: Historical Rules and Modern Mechanics, International Journal of Architectural Heritage, 1(2): 165-189.

[15] Pippard AJS, Ashby ERJ (1936). An experimental study of the voissour arch. Jour. Inst. Civ. Engrs., 10: 383-403.

[16] Hughes TG, Blackler MJ (1997). A review of the UK masonry arch assessment methods, Proc. Instn. Civ. Engrs., 122: 305-315.

[17] Fanning PJ, Boothby TE (2001). Three dimensional modelling and full scale testing of stone arch bridges. Computers and Structures, 79(29-30): 2645-2662.

[18] Fanning PJ, Boothby TE, Roberts BJ (2001). Longitudinal and transverse effects in masonry arch assessment. Construction and Building Materials, 15 (1): 51-60.

[19] Zeman, J., Nováka, J., Šejnoha, M., Šejnoha, J. (2008). Pragmatic multi-scale and multi-physics analysis of Charles Bridge in Prague. Engineering Structures 30 (11): 3365-3376.

[20] Luciano R, Sacco E (1997). Homogenisation technique and damage model for old masonry material. International Journal of Solids and Structures 34 (24): 3191-3208.

[21] Massart T, Peerlings RHJ, Geers MGD (2004). Mesoscopic modeling of failure and damageinduced anisotropy in brick masonry. Eur J Mech A/Solids 23: 719-35.

[22] Mercatoris BCN, Massart TJ, Bouillard P (2009). Multi-scale detection of failure in planar masonry thin shells using computational homogenisation. Eng Fract Mech 76(4): 479-499.

[23] Milani G, Milani E, Tralli A (2009). Upper Bound limit analysis model for FRP-reinforced masonry curved structures. Part II: structural analyses. Computers \& Structures 87 (23-24): 15341558.

[24] Lourenço PB, de Borst R, Rots JG (1997). A plane stress softening plasticity model for orthotropic materials. International Journal for Numerical Methods in Engineering 40: 4033-4057.

[25] Milani G, Tralli A (2011). Simple SQP approach for out-of-plane loaded homogenized brickwork panels accounting for softening. Computers \& Structures 89(1-2): 201-215.

[26] Orduña A, Lourenço PB (2005). Three-dimensional limit analysis of rigid blocks assemblages. Part II: Load-path following solution procedure and validation, Int. J. Solids and Structures, 42(18-19): 5161-5180.

[27] Wang J, Melbourne C (1996). The 3-Dimensional Behaviour of Skew Masonry Arches. In: Proc. 7th bristish masonry conference, The British Masonry Society, London, UK.

[28] Melbourne C, Hodgson JA (1996). The behavior of skewed brickwork arch bridges. In: Arch Bridges (Ed. Melbourne): 309-320.

[29] Melbourne C, Gilbert M (1995). The behavior of multi-ring brickwork arch bridges. Structural Engr. 73(3).

[30] Gilbert M (2001). Ring: a 2D rigid block analysis program for masonry arch bridges. In: Proc. $3^{\text {rd }}$ international arch bridges conference, Paris, France: 109-118. 
[31] Milani G, Lourenco PB, Tralli A (2006). Homogenization approach for the limit analysis of outof-plane loaded masonry walls. Homogenised limit analysis of masonry walls. Part II: structural examples. Computers and Structures 84(3-4): 181-195.

[32] Milani G, Tralli A (2012). A simple meso-macro model based on SQP for the non-linear analysis of masonry double curvature structures. International Journal of Solids and Structures, 49(5): 808834.

[33] De Donato O, Franchi A (1973). A modified gradient method for finite element elastoplastic analysis by quadratic programming. Computer Methods in Applied Mechanics and Engineering 2(2): 107-131.

[34] Kawai T (1978). New discrete models and their application to seismic response analysis of structures. Nuclear Engineering and Design 48: 207-229.

[35] Orduna A (2005). Seismic assessment of ancient masonry structures by rigid blocks limit analysis. $\mathrm{PhD}$ thesis, University of Minho, PT.

[36] Cecchi A, Milani G (2008). A kinematic FE limit analysis model for thick English bond masonry walls. International Journal of Solids and Structures 45(5): 1302-1331.

[37] Sloan SW, Kleeman PW (1995). Upper bound limit analysis using discontinuous velocity fields. Comput. Meth. Appl. Mech. Eng. 127(1-4): 293-314.

[38] Milani G, Casolo S, Naliato A, Tralli A (2012). Seismic assessment of a medieval masonry tower in Northern Italy by limit, non-linear static and full dynamic analyses. International Journal of Architectural Heritage. In press.

[39] Strand7.2 G+D computing (2004). Theoretical Manual /www.strand7.com. 


\section{Figures}
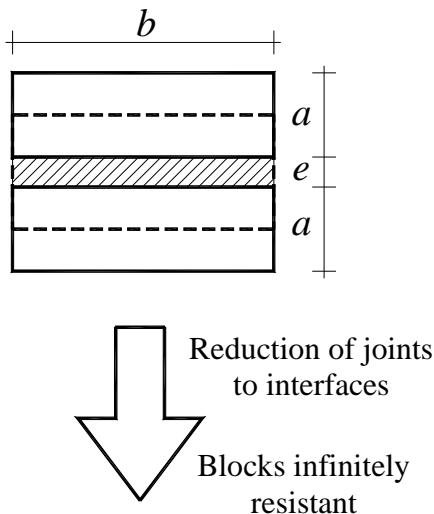

Mortar tensile behavior
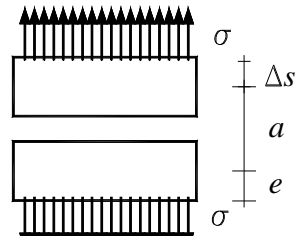

Mortar compressive behavior

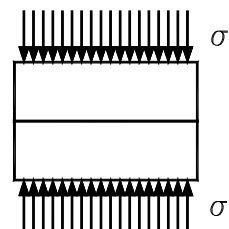

Mortar shear behavior

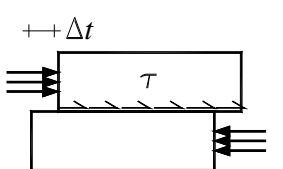

Mortar joint interfacial behavior

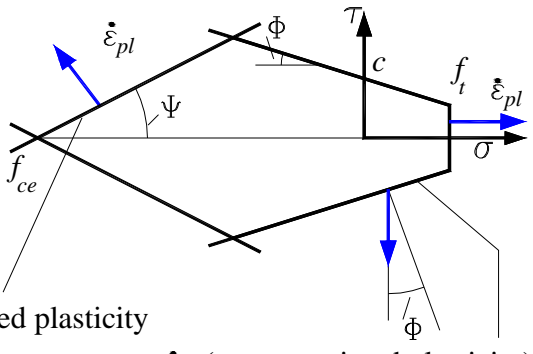

$\dot{\varepsilon}_{\text {pl }}$ (non-associated plasticity)

associated plasticity
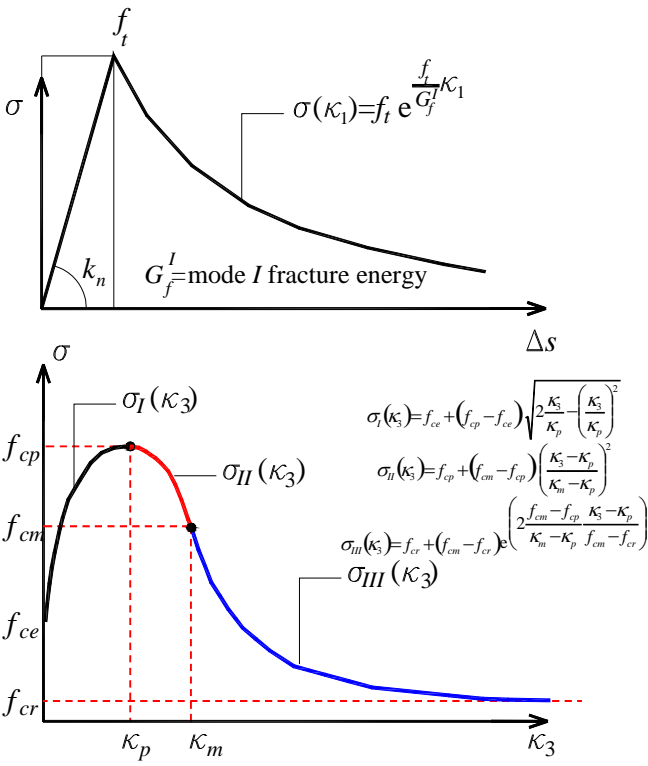

$G_{m}=$ mortar
shear modulus
$G_{b}=$ brick
shear modulus
$k_{t}=\frac{G_{m} G_{b}}{e\left(G_{b}-G_{m}\right)}$

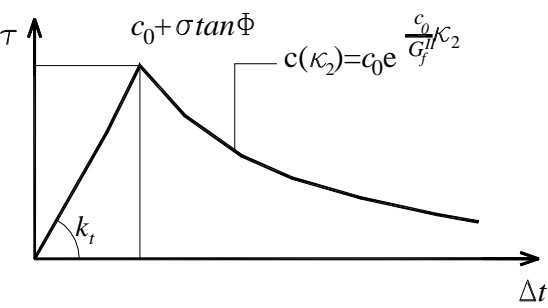

Figure 1: Mortar joints non-linear behavior. 


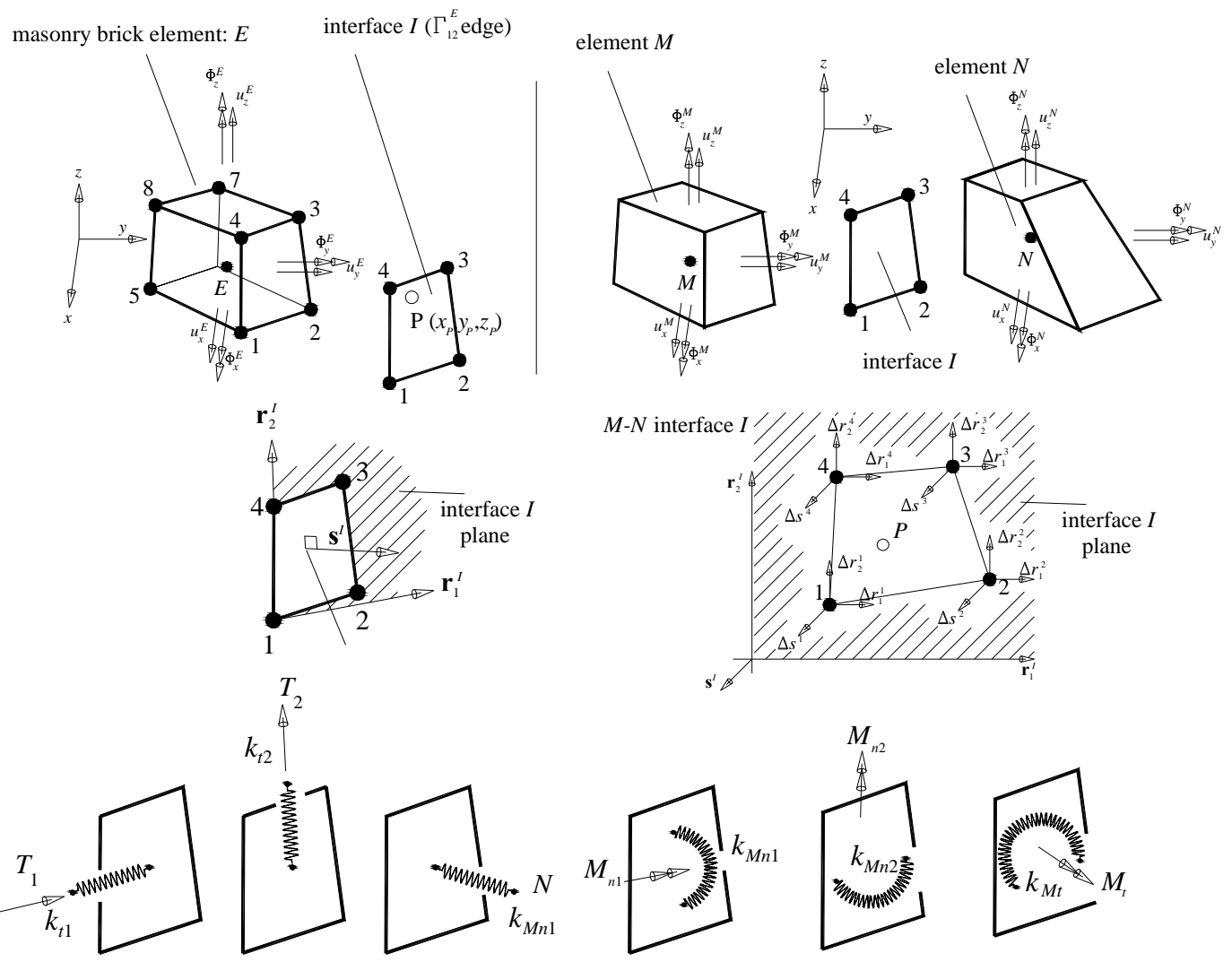

Figure 2: Rigid infinitely resistant eight-noded parallepiped element used for bridges 3D discretization and kinematics of interfaces between contiguous elements. 

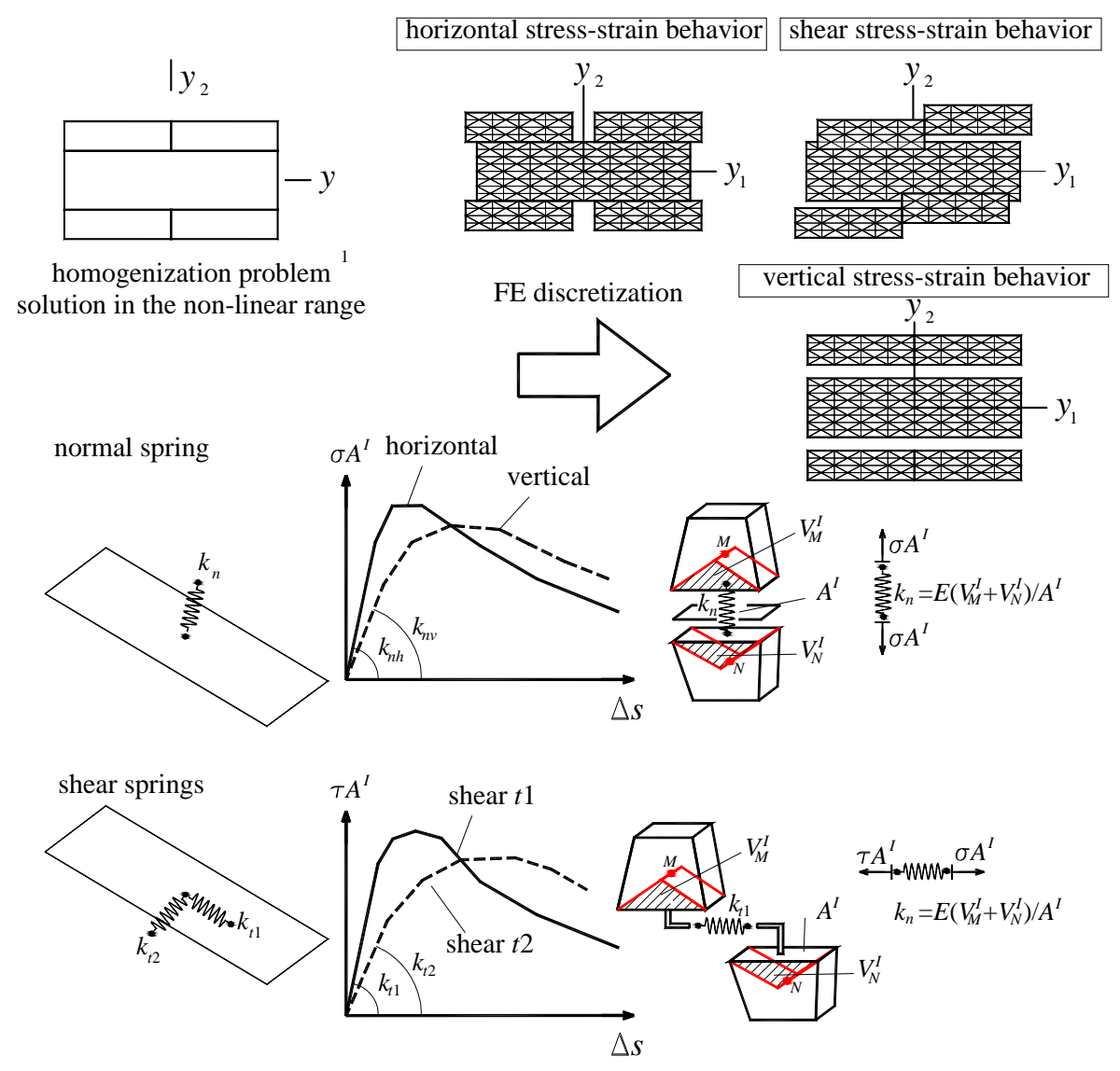

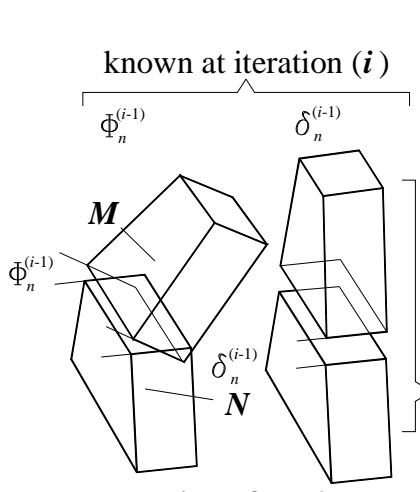

interface $k$
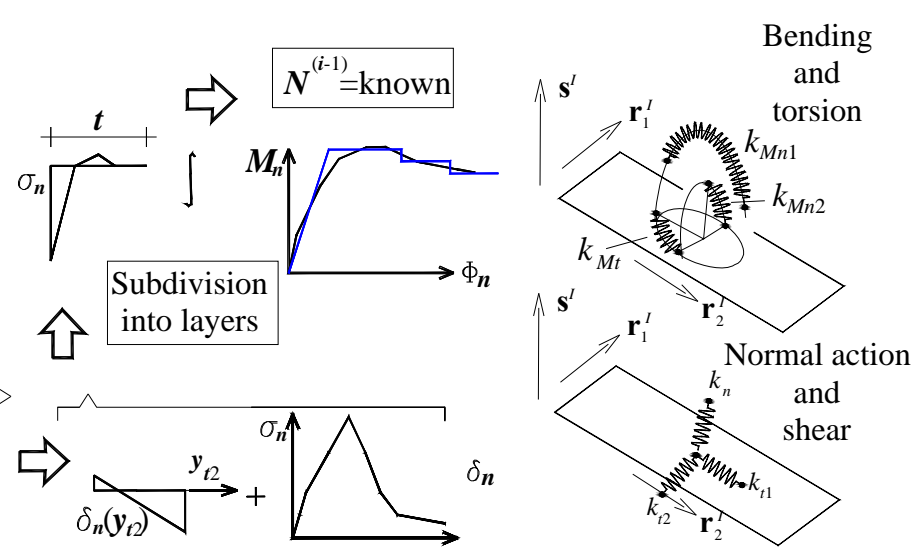

Figure 3: -a: Interfaces normal and shear springs non-linear behavior derived by homogenization. b: Approximate approach to take into account bending in-plane actions interactions. 


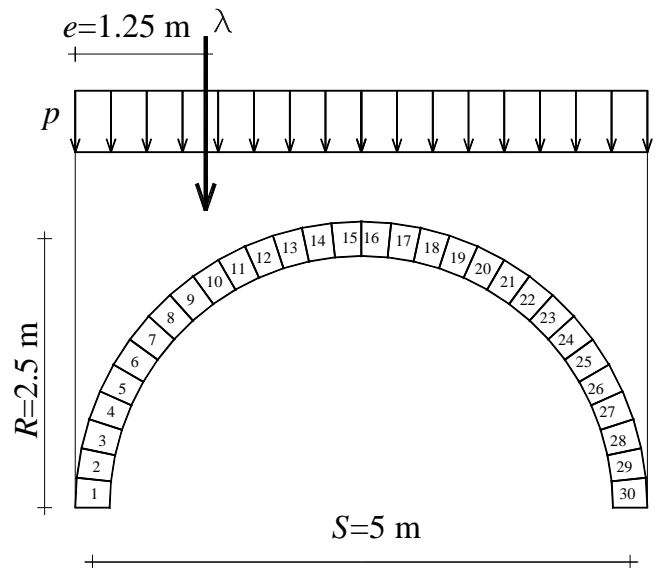

$-\mathrm{a}$

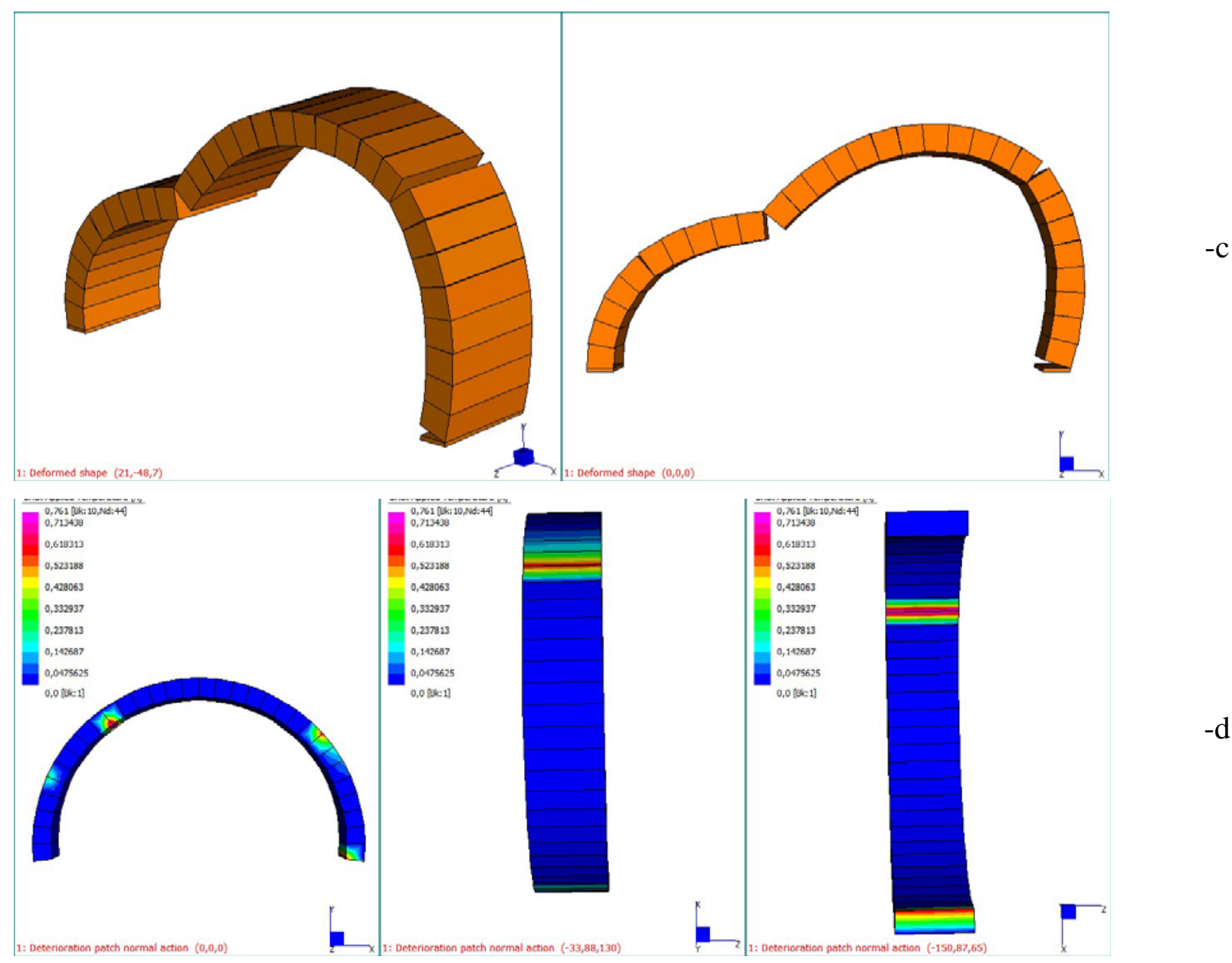

Figure 4: Semi-circular arch benchmark example. -a: geometry and loads. -b: load-vertical displacement curves. - c: deformed shape at collapse. - d: Degraded interfaces patch (from 0 -no degradation- to 1 -full degradation) obtained through the non-linear homogenized FE code proposed. Positive normal stress. 
Backfill
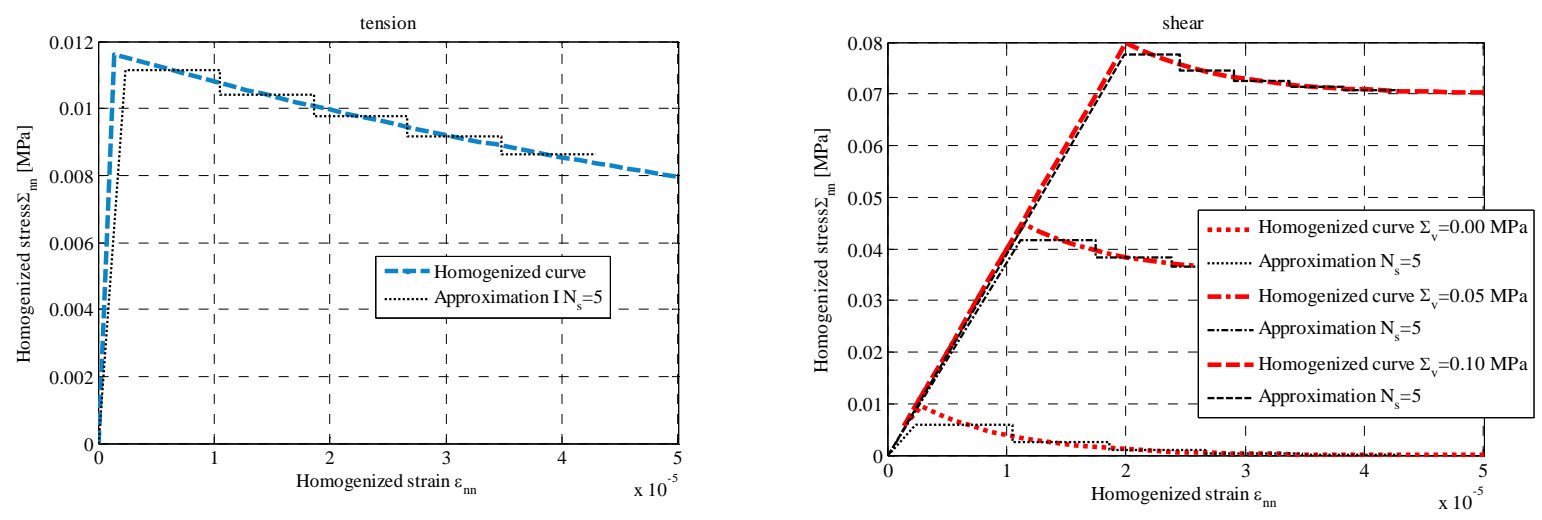

Spandrels
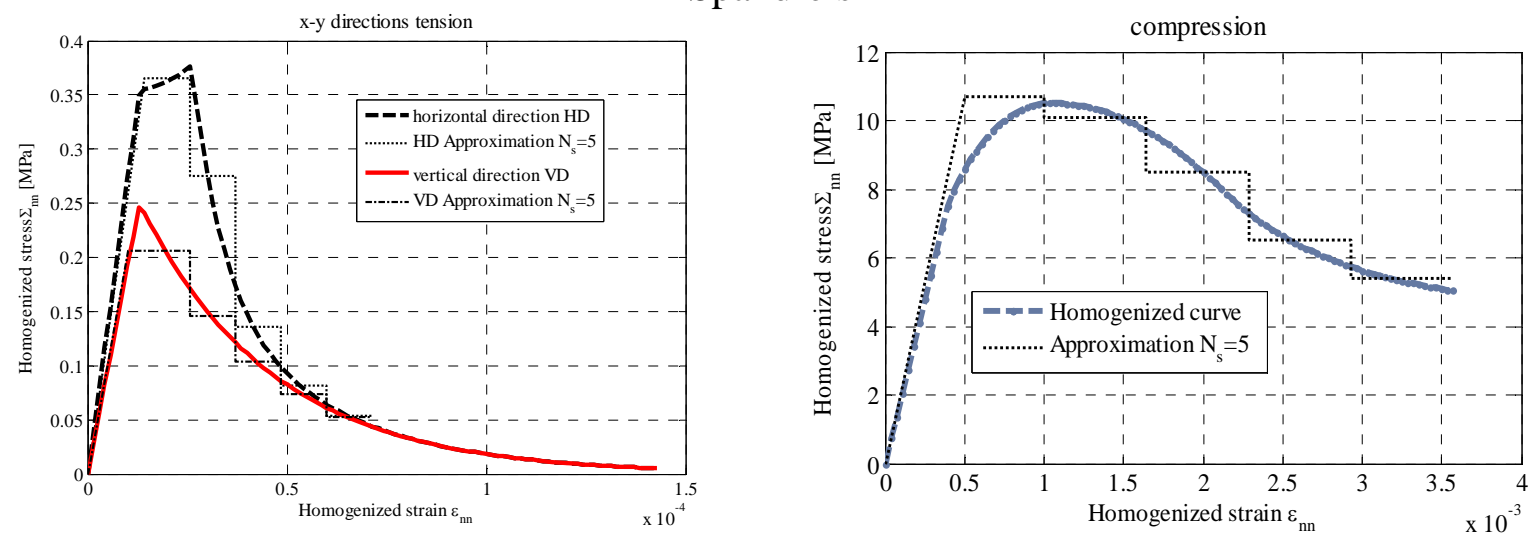

Arch
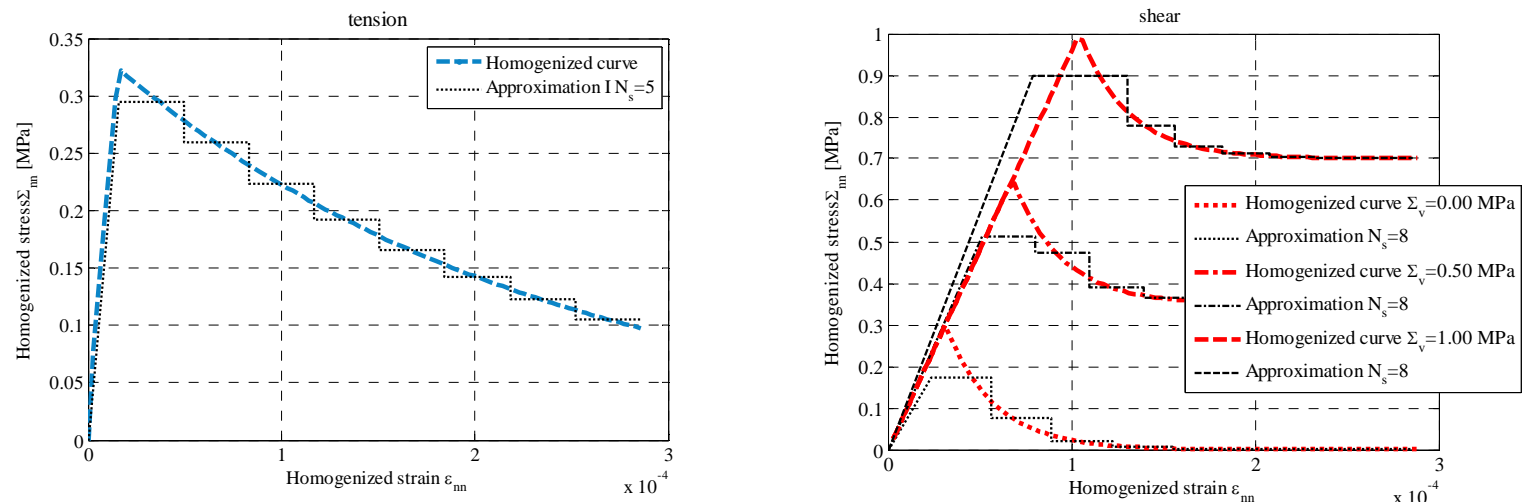

Figure 5: Bolton institute bridge stress-strain relationships used for spandrels, backfill and arch. 


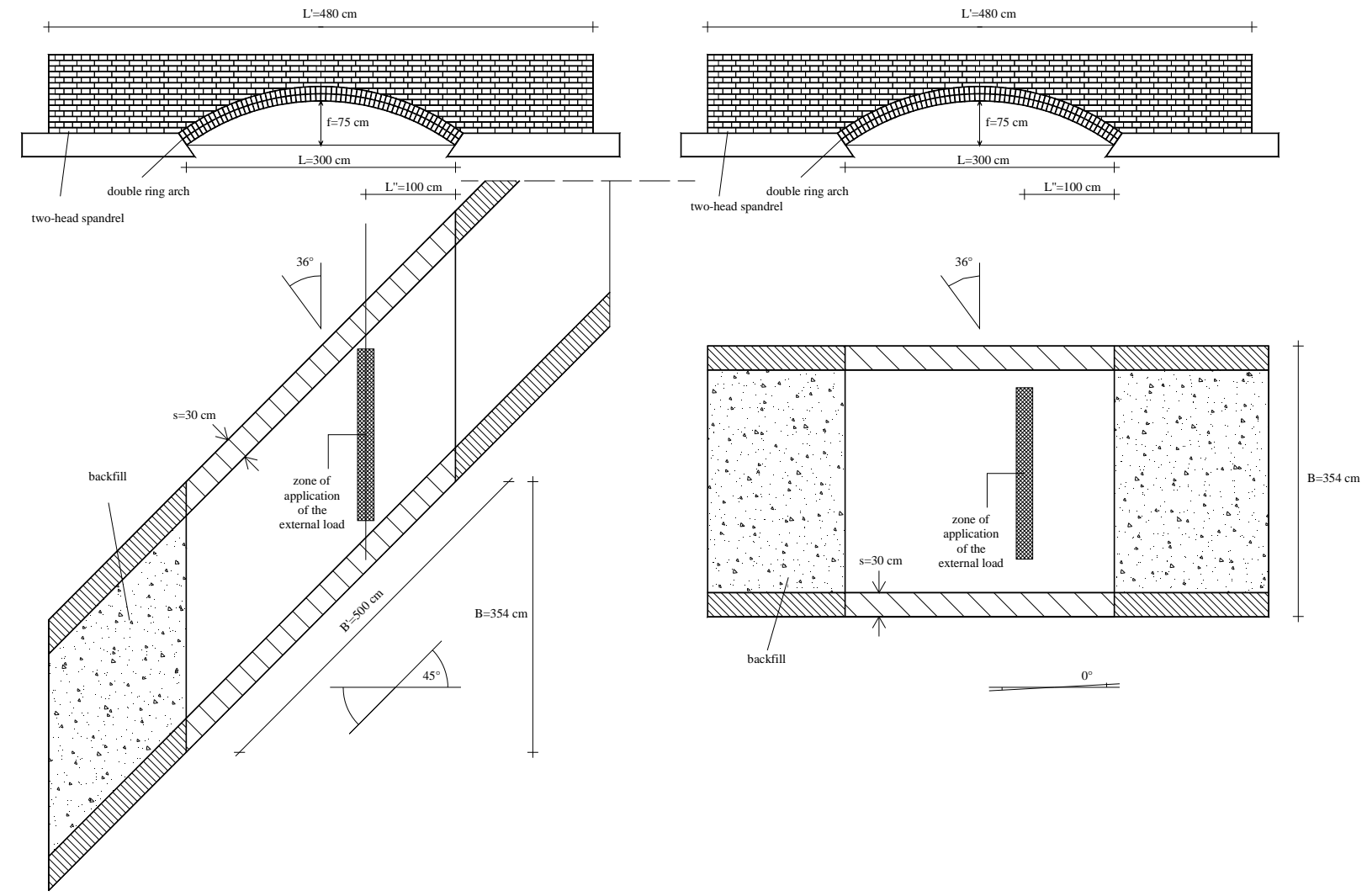

Figure 6: Bolton institute bridges (right and skew). Geometry, loads and FE discretization adopted for the numerical simulations. 

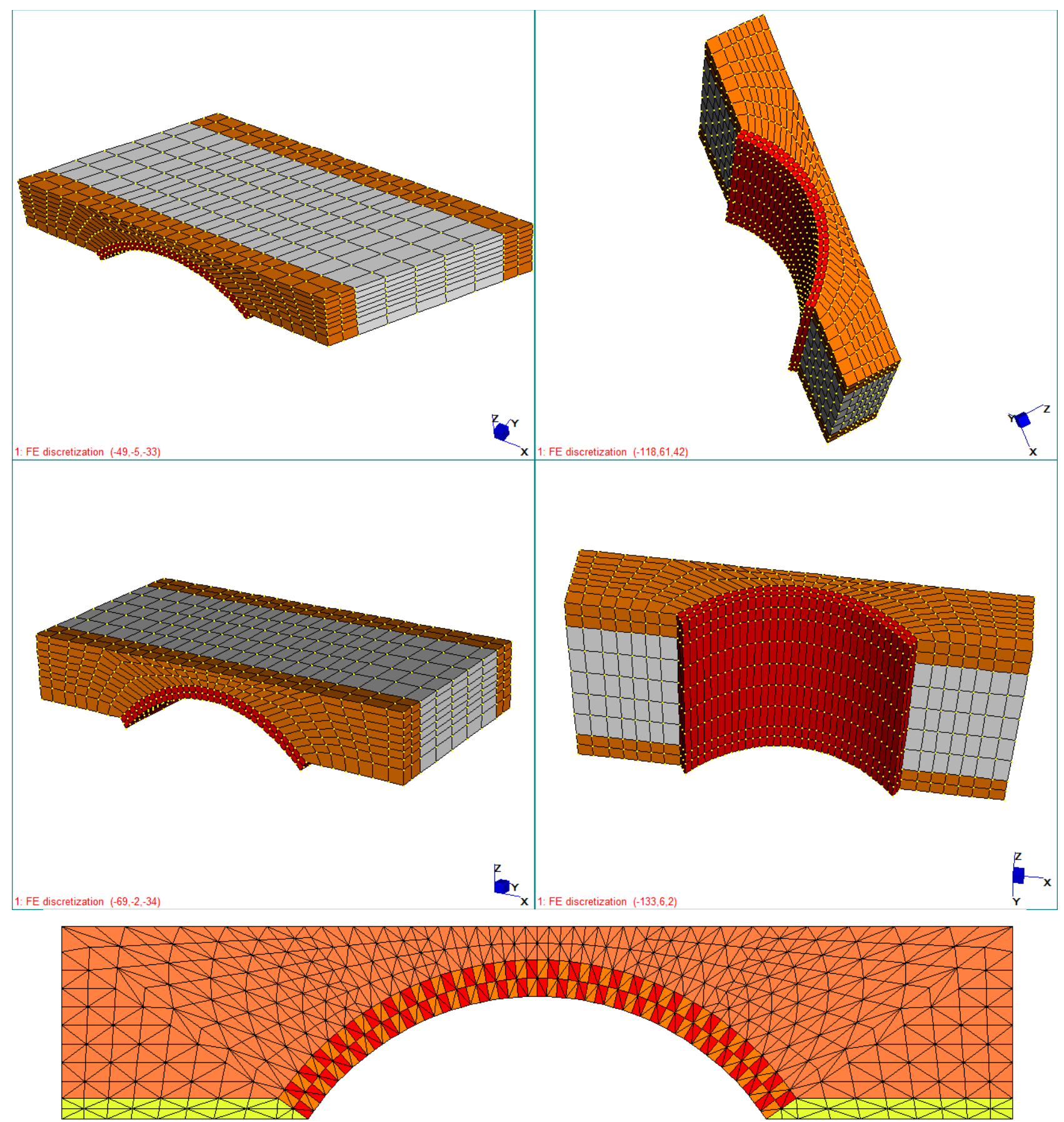

Figure 7: FE meshes used for the numerical simulations. Top: 3D non linear model, skew arch (2016 brick elements, 2700 nodes). Center: 3D non linear model right arch (2016 brick elements, 2700 nodes). Bottom: 2D limit analysis model with arch-fill interaction. 

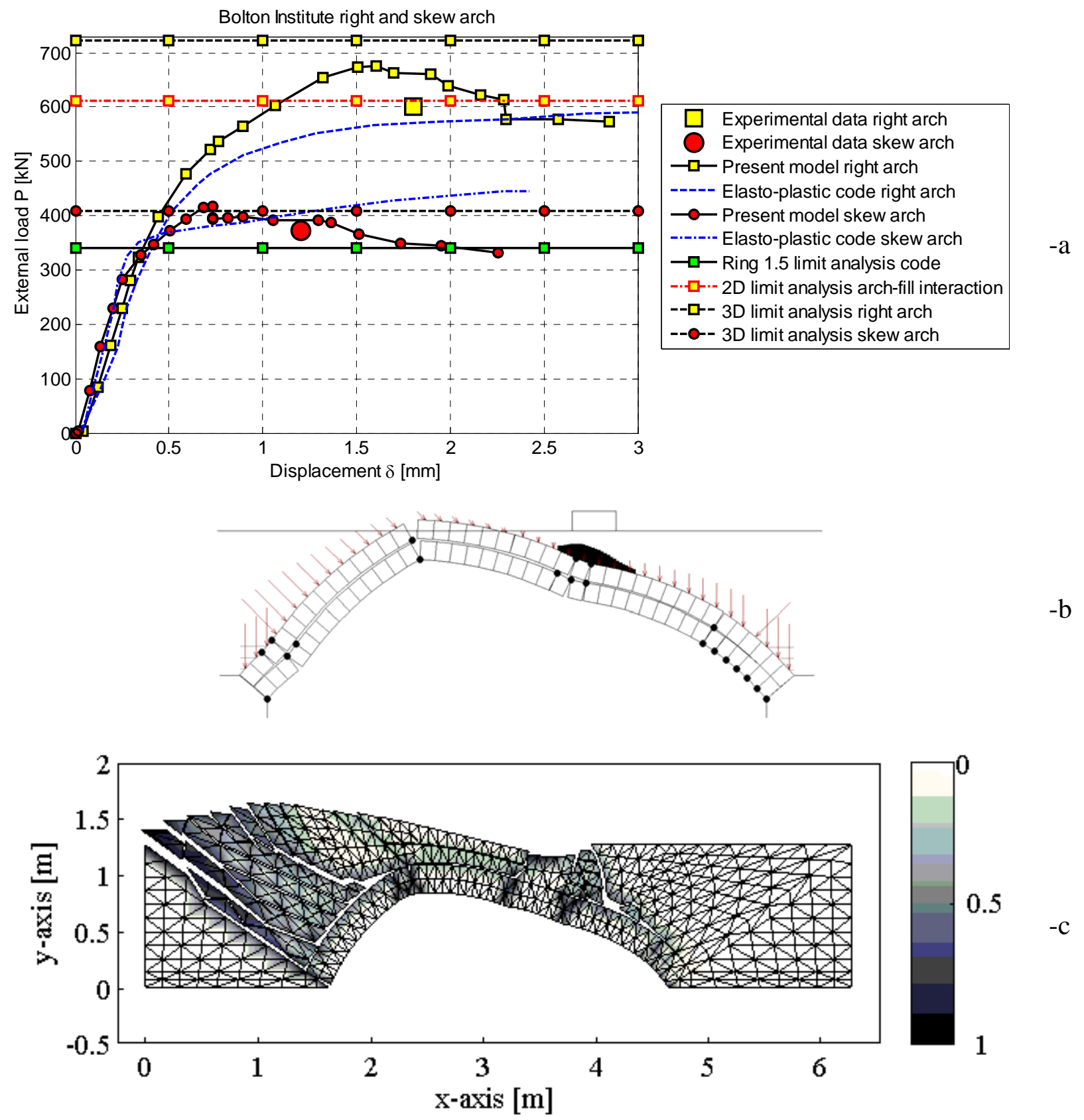

Figure 8: -a: Vertical load-maximum vertical displacement curves obtained with the model proposed. In the figure experimental data available, collapse loads provided by Ring 1.5, 2D FE limit analysis with arch-fill interaction, 3D FE limit analysis and elasto-plastic FE models are also represented. -b: deformed shape at collapse obtained with Ring 1.5. $-\mathrm{c}$ : deformed shape at collapse obtained with the 2D limit analysis code with arch-fill interaction 

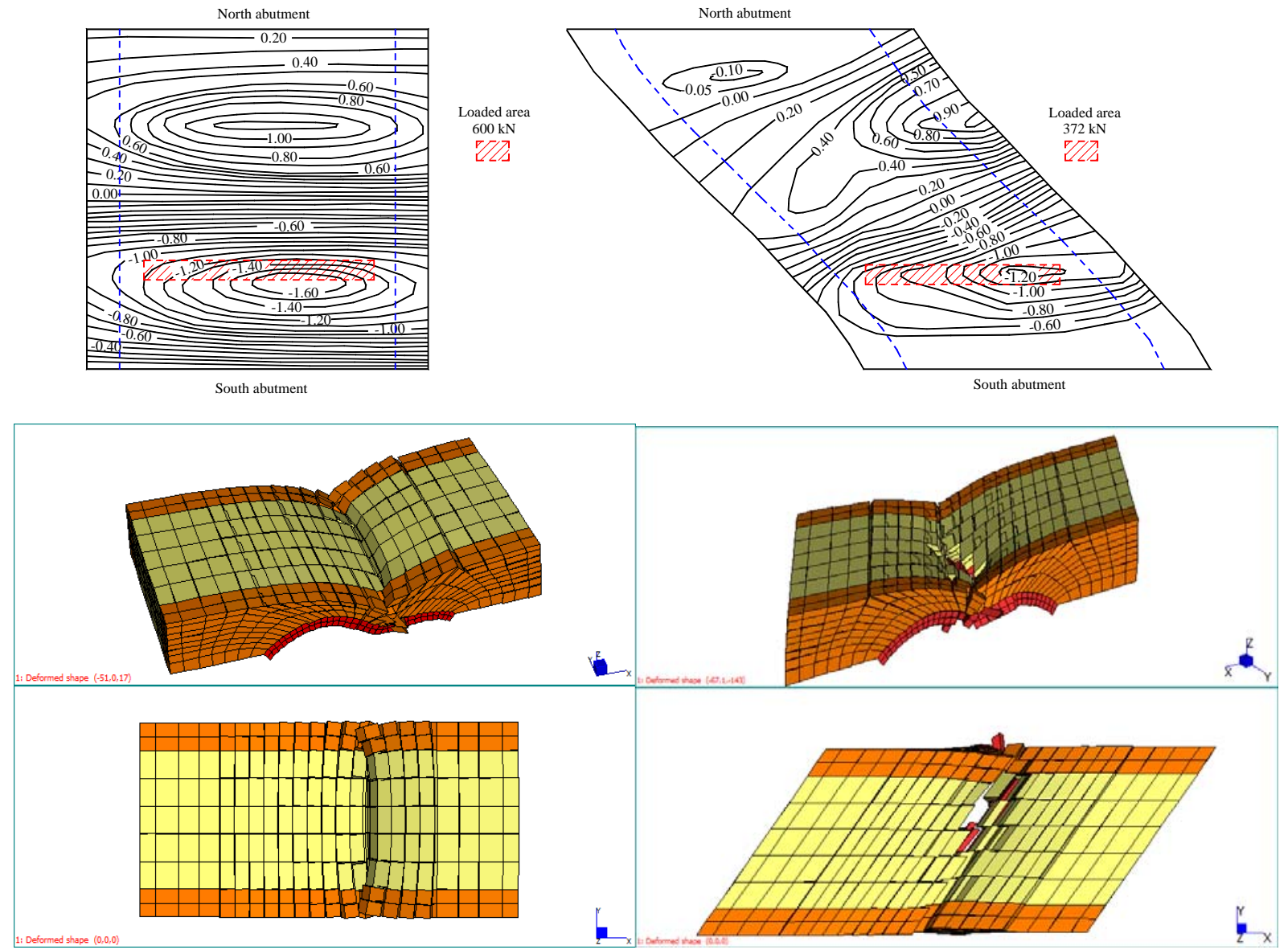

Figure 9:Top: Experimental displacement contour map at failure for the right and skew arch. Bottom: deformed shapes at peak obtained with the FE code proposed (left: right arch, right: skew arch). 


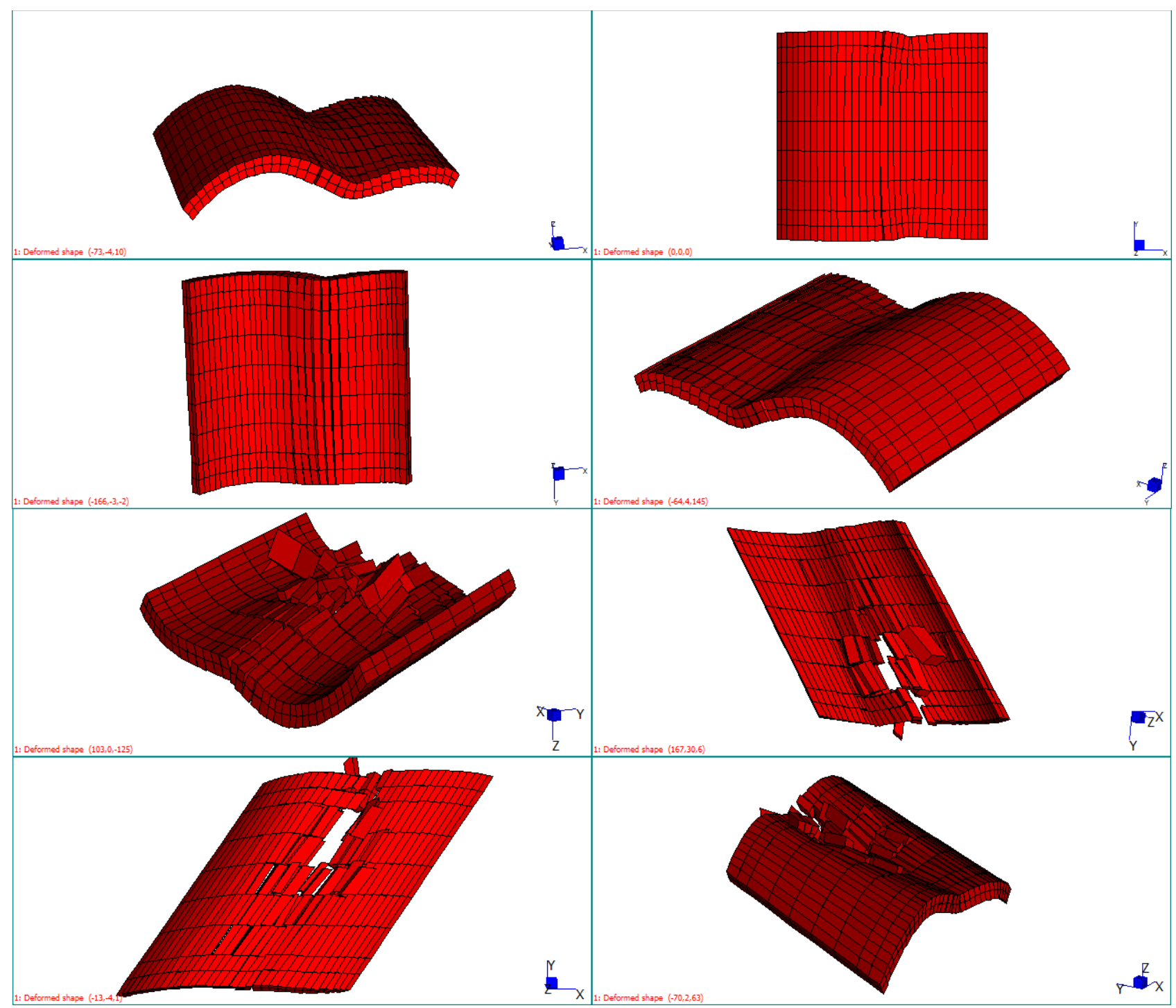

Figure 10: Bolton Institute masonry arch bridges. Deformed shape of the arch. Top: right arch. Bottom: skew arch. 


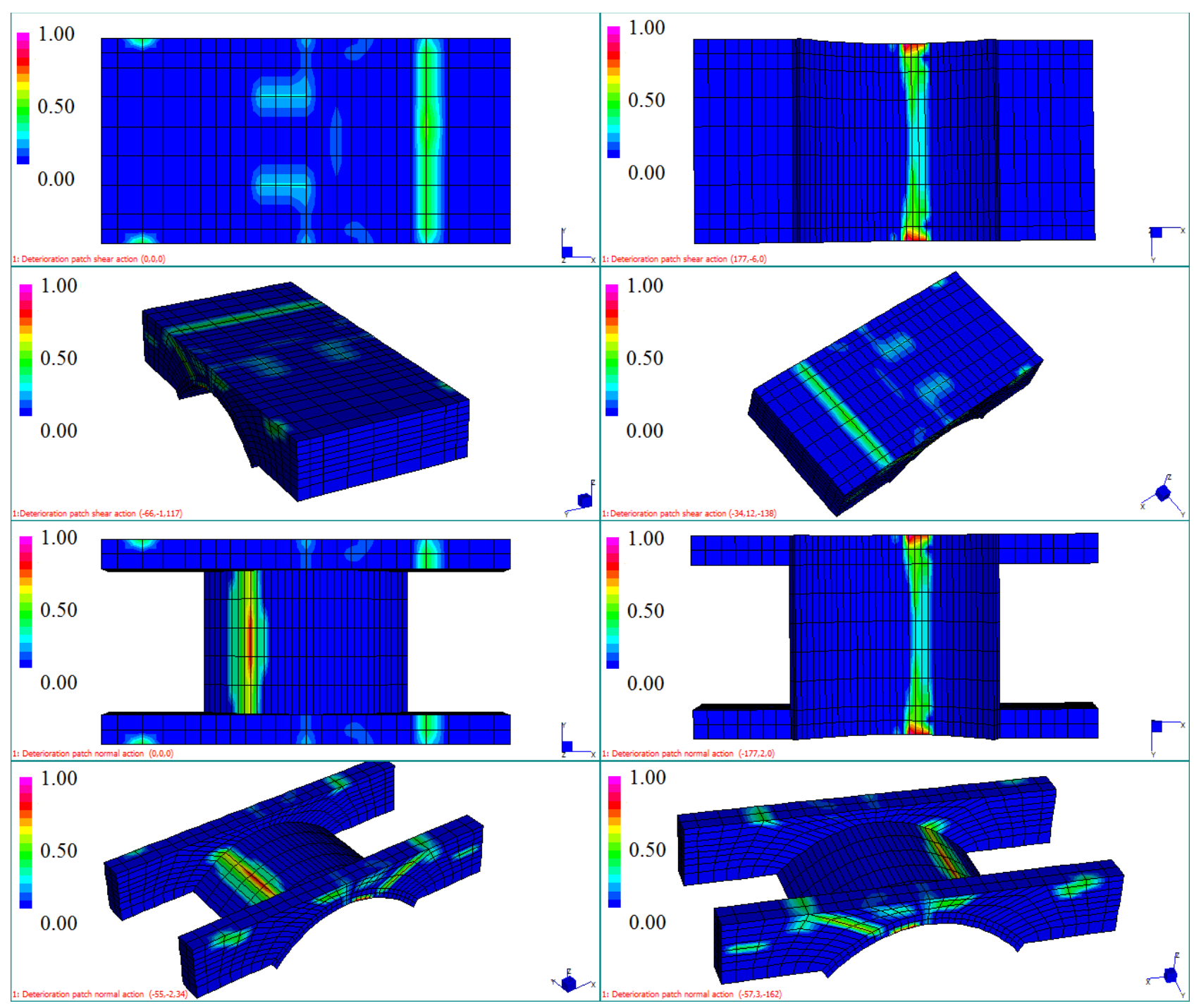

Figure 11: Bolton Institute masonry arch bridges. Right arch. Degraded interfaces patch (from 0 -no degradation- to 1 -full degradation) obtained through the non-linear homogenized FE code proposed. Positive normal stress. 


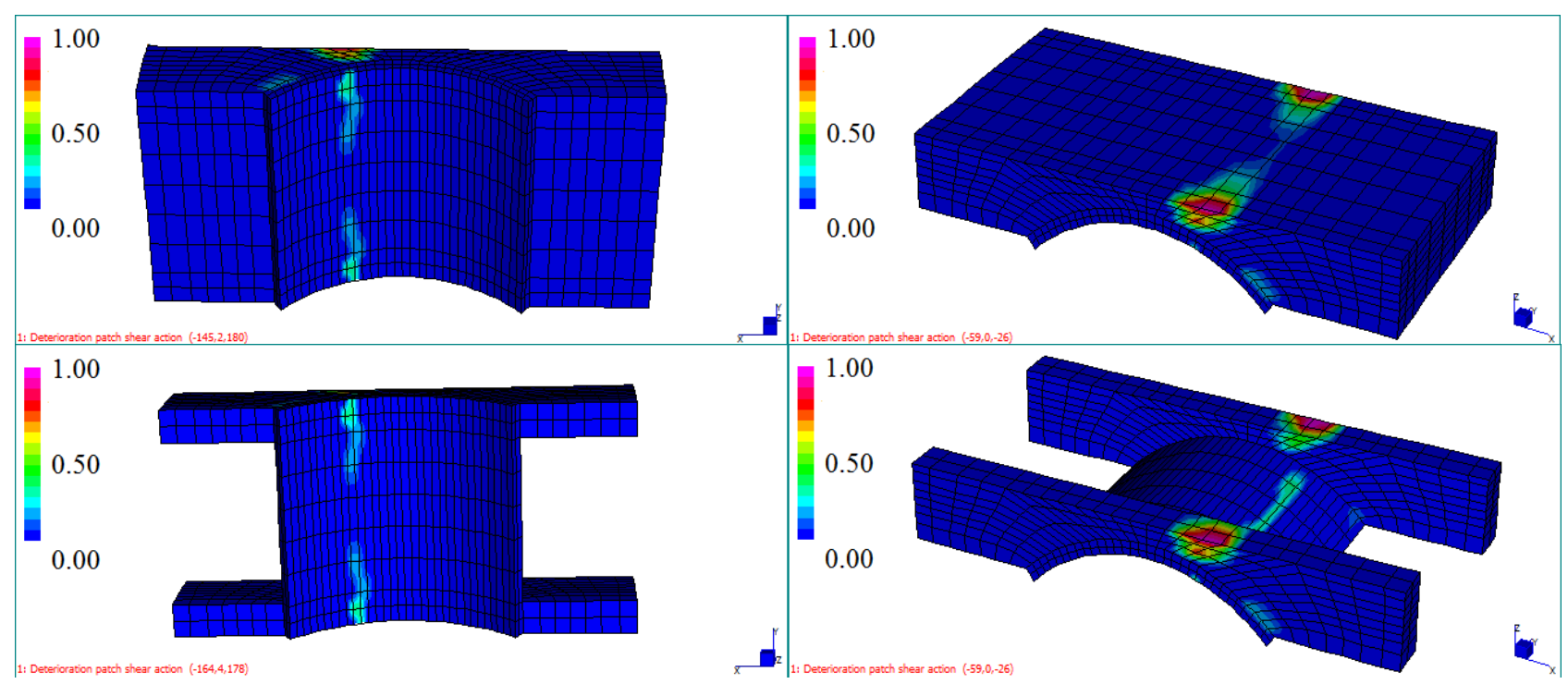

Figure 12: Bolton Institute masonry arch bridges. Right arch. Degraded interfaces patch (from 0 -no degradation- to 1 -full degradation) obtained through the non-linear homogenized FE code proposed. In- and out-of-plane shear. 


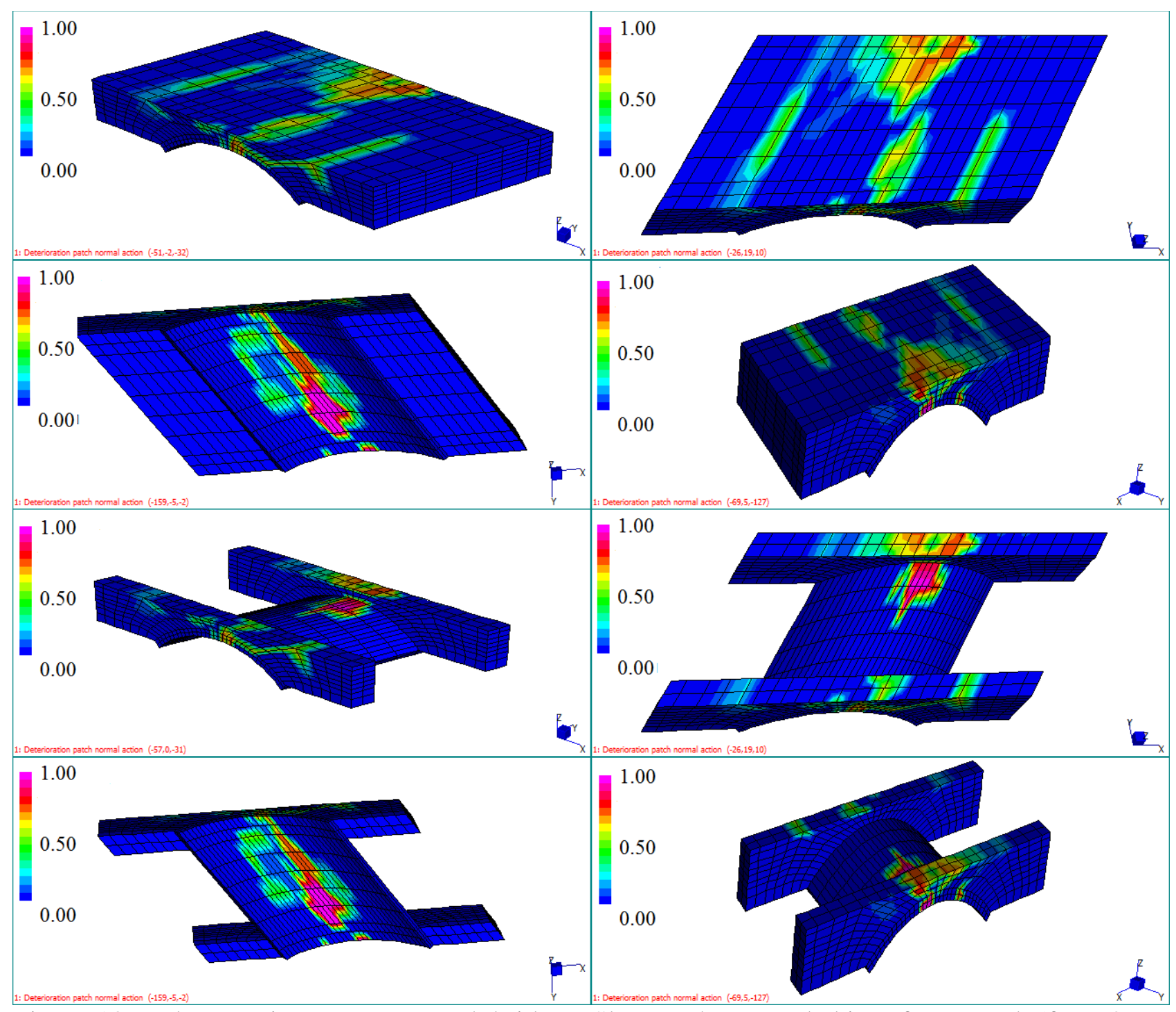

Figure 13: Bolton Institute masonry arch bridges. Skew arch. Degraded interfaces patch (from 0 -no degradation- to 1 -full degradation) obtained through the non-linear homogenized FE code proposed. Positive normal stress. 


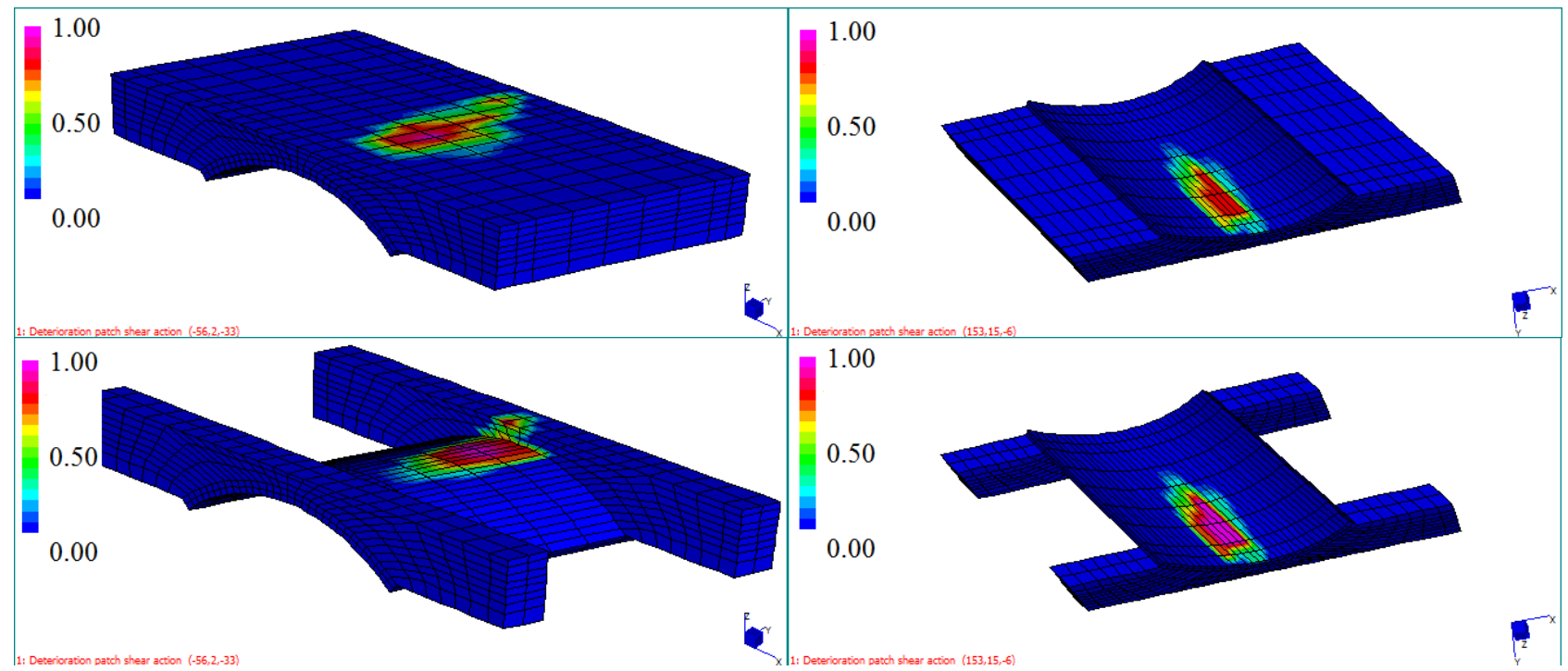

Figure 14: Bolton Institute masonry arch bridges. Skew arch. Degraded interfaces patch (from 0 -no degradation- to 1 -full degradation) obtained through the non-linear homogenized FE code proposed. In- and out-of-plane shear.
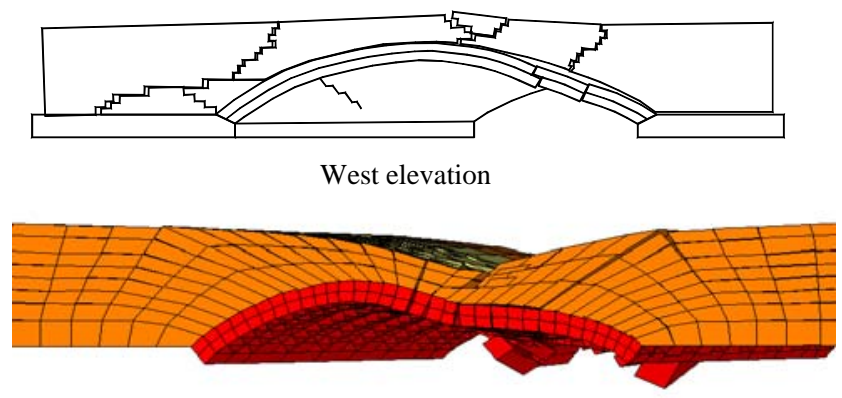

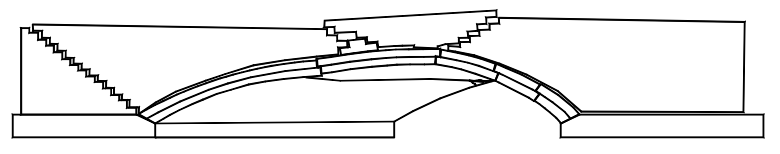

East elevation

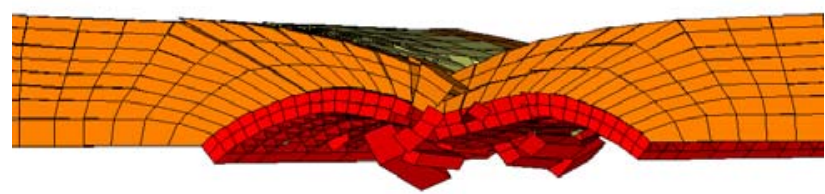

Figure 15: Bolton Institute masonry skew arch. Comparison between experimental and numerical spandrels failure mechanisms. 

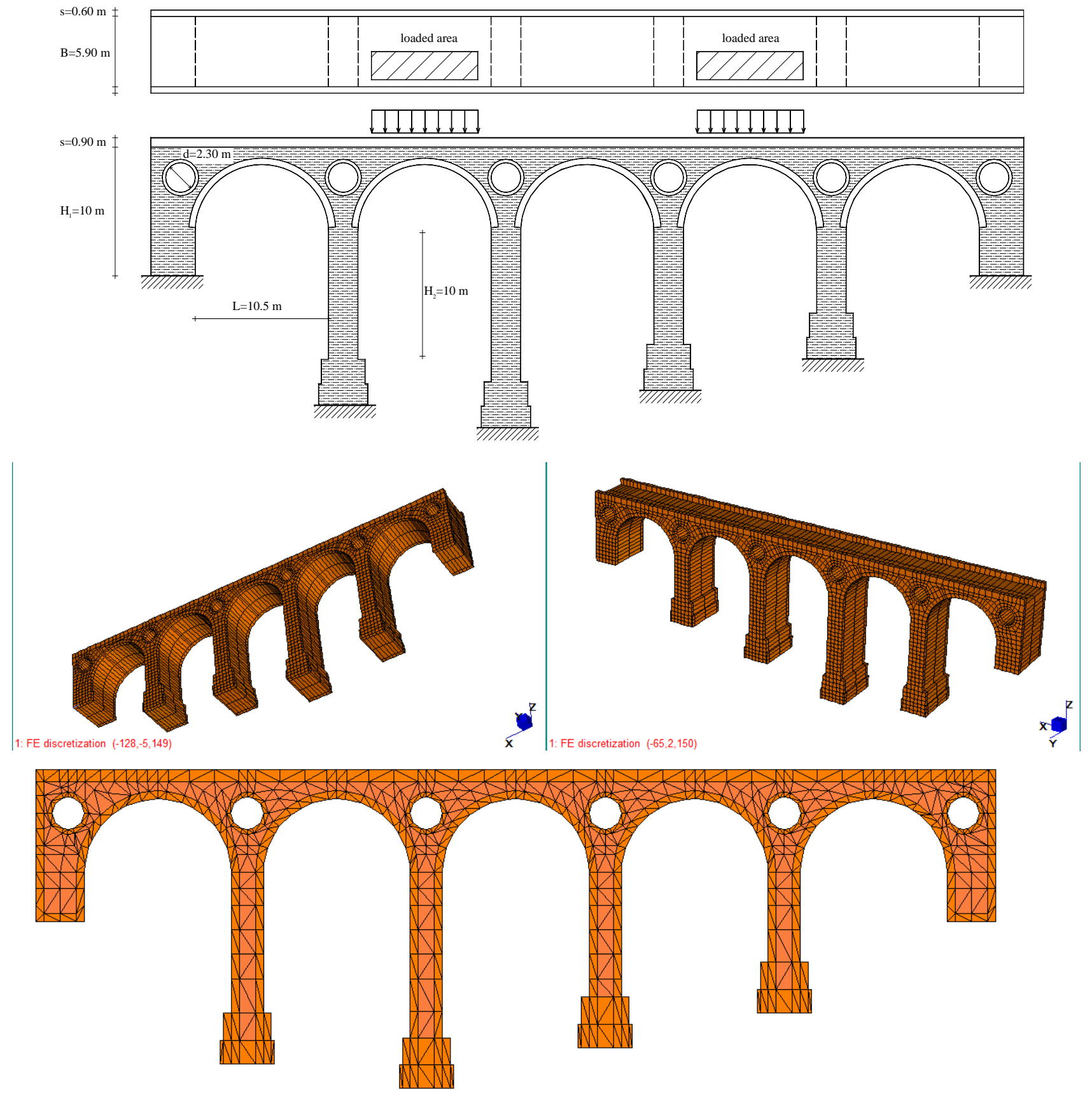

Figure 16: Five-span arch bridge. Top: Geometry and loading condition. Bottom: FE discretization 


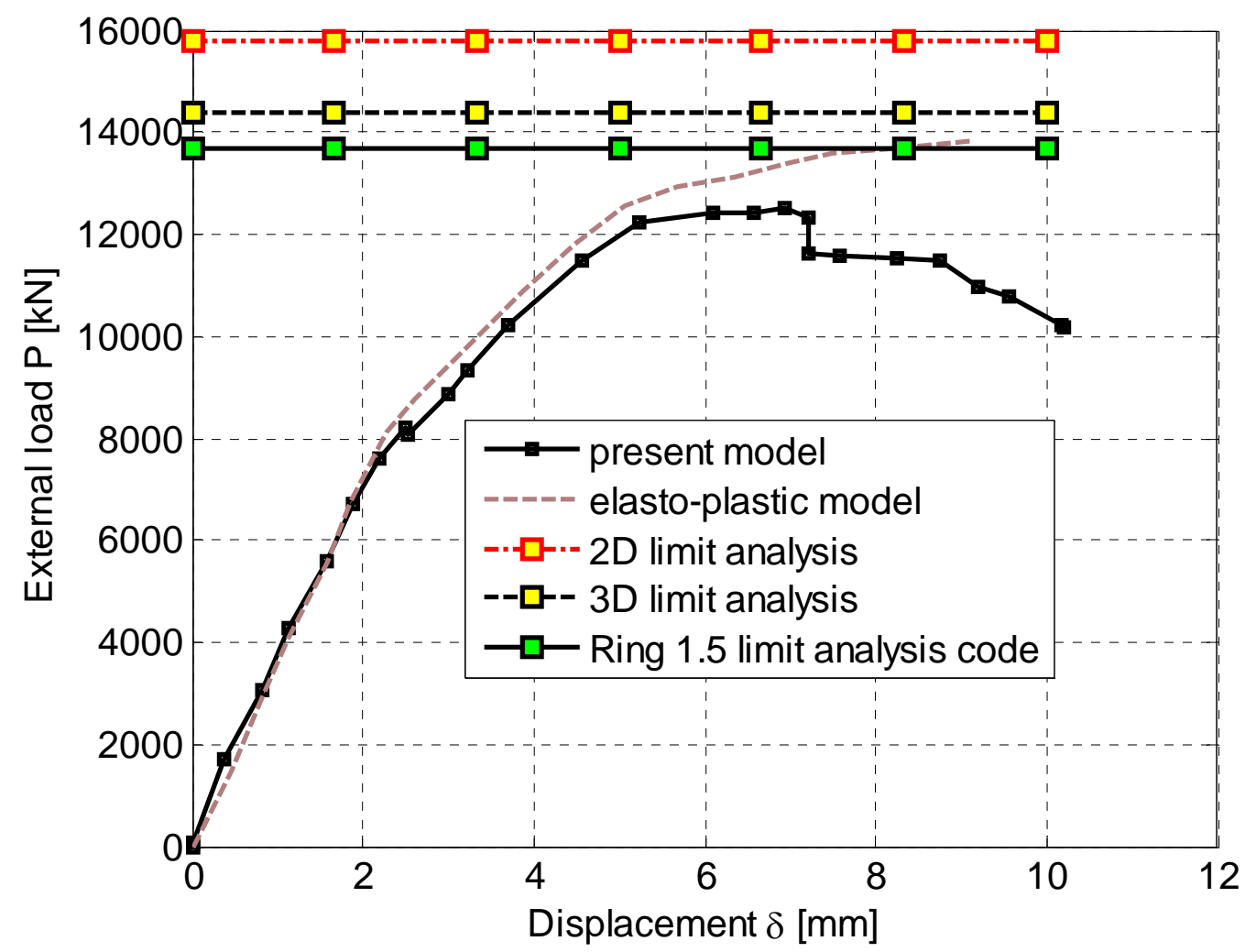

Figure 17: Five-span arch bridge. Vertical load-maximum vertical displacement curves obtained with the model proposed. In the figure collapse loads provided by Ring 1.5, 2D FE limit analysis with arch-fill interaction, 3D FE limit analysis and elasto-plastic FE models are also represented. 

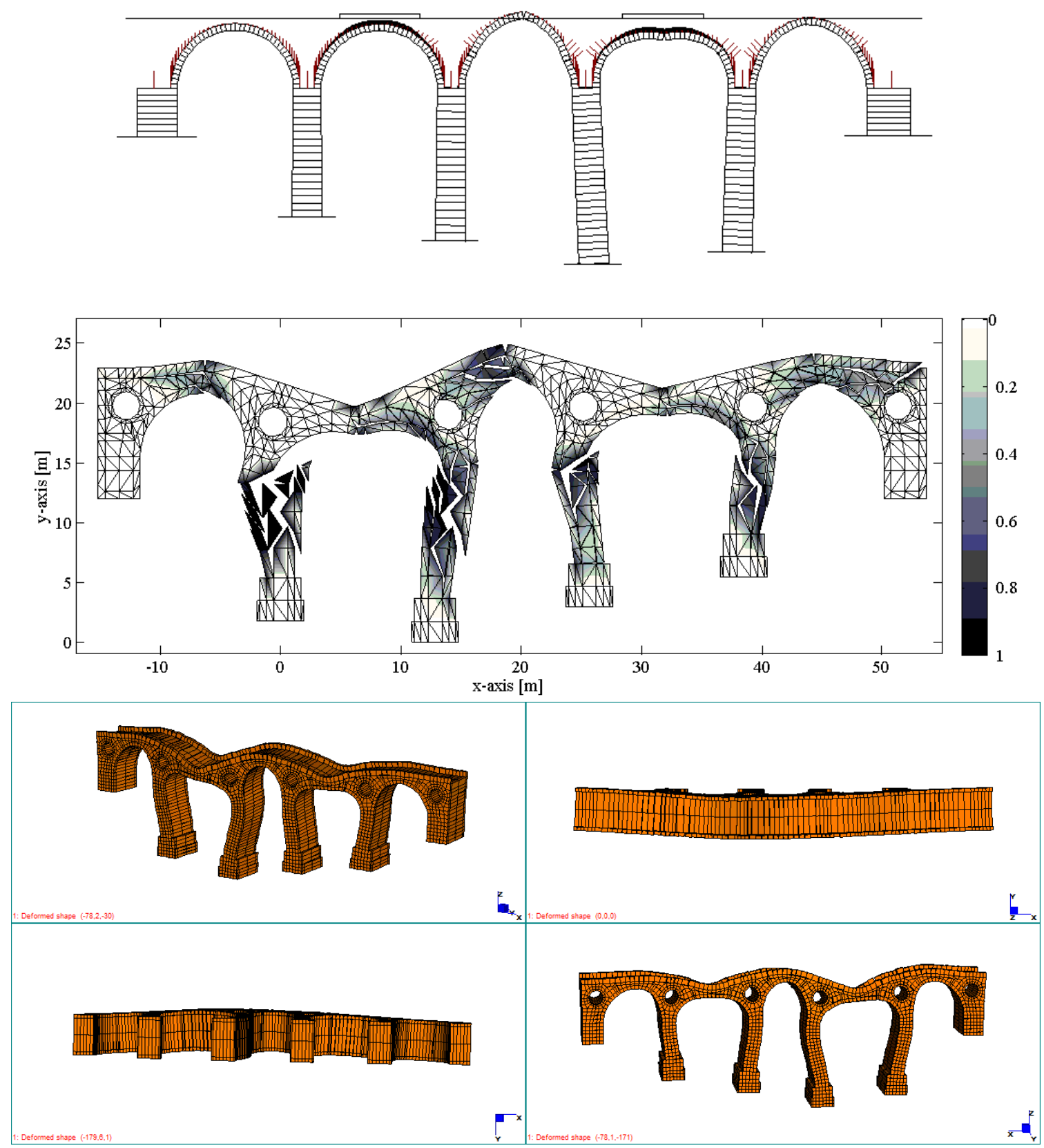

$-\mathrm{C}$

Figure 18: Five-span arch bridge. -a deformed shape at collapse obtained with Ring 1.5. -b: deformed shape and power dissipation patch obtained with a kinematic 2D limit analysis. -c: deformed shape obtained with the present numerical model (3D effects are also put in evidence) 


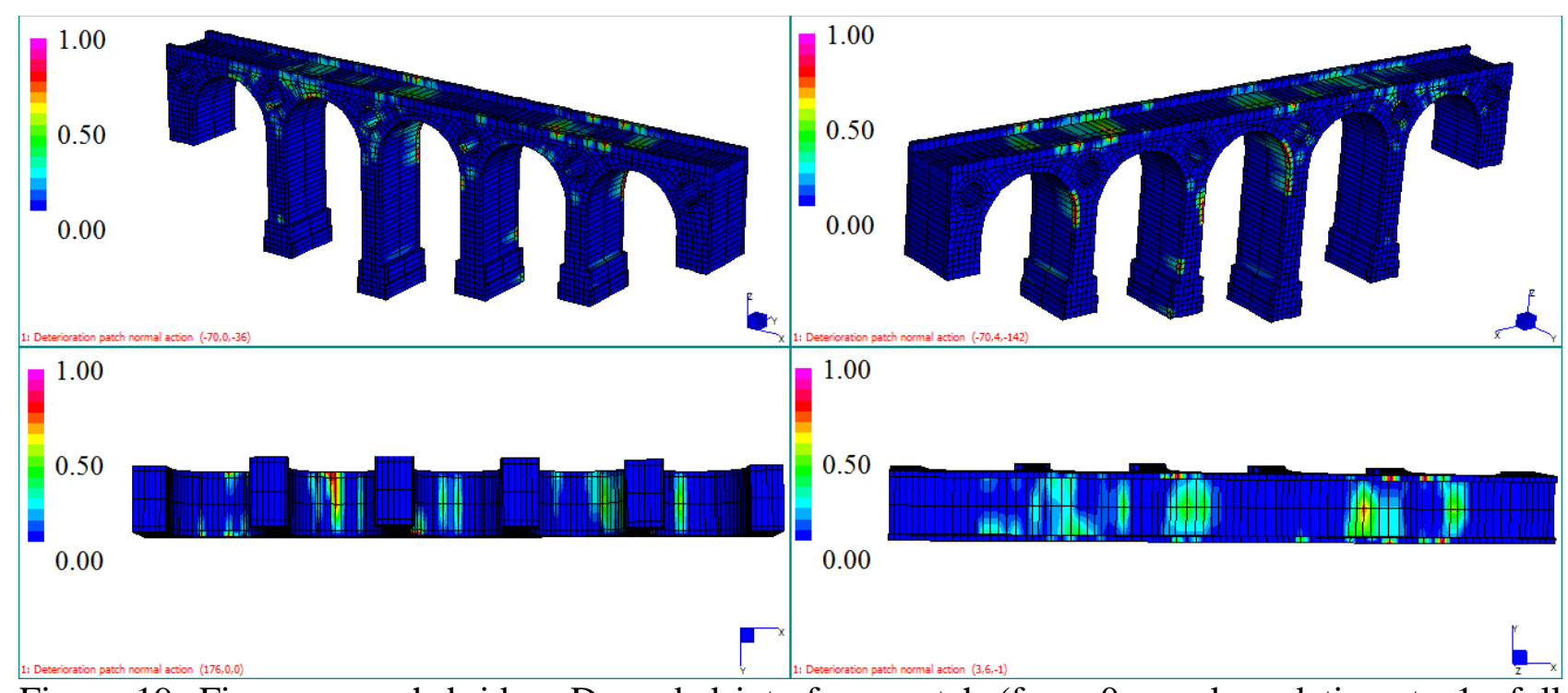

Figure 19: Five-span arch bridge. Degraded interfaces patch (from 0 -no degradation- to 1 -full degradation) obtained through the non-linear homogenized FE code proposed. Positive normal stress. 


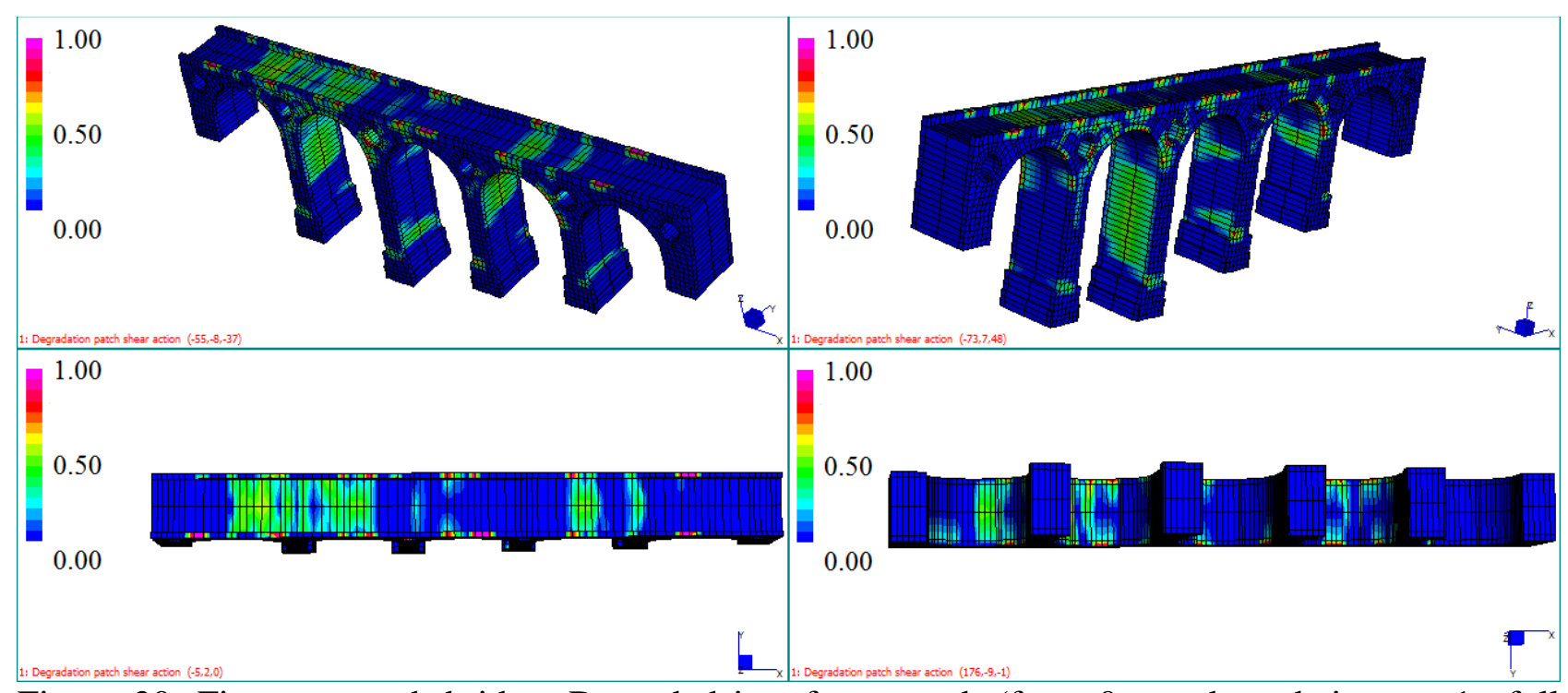

Figure 20: Five-span arch bridge. Degraded interfaces patch (from 0 -no degradation- to 1 -full degradation) obtained through the non-linear homogenized FE code proposed. In- and out-of-plane shear. 
Tables

\begin{tabular}{|c|c|c|c|c|}
\hline \multicolumn{5}{|c|}{ Masonry interfaces } \\
\hline$E$ & & 18000 & [MPa] & Young Modulus \\
\hline$G$ & & $\mathrm{E} / 2$ & [MPa] & Shear Modulus \\
\hline$C$ & & $1.0 f_{t}$ & [MPa] & Cohesion \\
\hline$f_{t}$ & & 0.30 & {$[\mathrm{MPa}]$} & Tensile strength \\
\hline$f_{c e}$ & $1 / 3 f_{c p}$ & - & [MPa] & \multirow{6}{*}{$\begin{array}{c}\text { Compressive } \\
\text { hardening/softening } \\
\text { behavior }\end{array}$} \\
\hline$f_{c p}$ & \multicolumn{2}{|r|}{28} & {$[\mathrm{MPa}]$} & \\
\hline$f_{c m}$ & $1 / 2 f_{c p}$ & \multirow{2}{*}{-} & [MPa] & \\
\hline$f_{c r}$ & $1 / 7 f_{c p}$ & & {$[\mathrm{MPa}]$} & \\
\hline$\kappa_{p} / e_{h}$ & 0.009 & - & {$[-]$} & \\
\hline$\kappa_{m} / e_{h}$ & 0.049 & - & {$[-]$} & \\
\hline$\Phi$ & 37 & 45 & {$\left[{ }^{\circ}\right]$} & Friction angle \\
\hline$\Psi$ & 45 & - & {$\left[{ }^{\circ}\right]$} & $\begin{array}{c}\text { Angle of the } \\
\text { linearized } \\
\text { compressive cap }\end{array}$ \\
\hline$G_{f}^{I}$ & 0.010 & 10 & {$[\mathrm{~N} / \mathrm{mm}]$} & $\begin{array}{l}\text { Mode I fracture } \\
\text { energy }\end{array}$ \\
\hline$G_{f}^{I I}$ & 0.0050 & 10 & {$[\mathrm{~N} / \mathrm{mm}]$} & $\begin{array}{l}\text { Mode II fracture } \\
\text { energy }\end{array}$ \\
\hline \multicolumn{5}{|c|}{ Backfill } \\
\hline$E$ & \multicolumn{2}{|r|}{3200} & [MPa] & Young Modulus \\
\hline$G$ & \multicolumn{2}{|r|}{$\mathrm{E} / 2$} & [MPa] & Shear Modulus \\
\hline$C$ & \multicolumn{2}{|r|}{$1.0 f_{t}$} & [MPa] & Cohesion \\
\hline$f_{t}$ & \multicolumn{2}{|r|}{0.05} & [MPa] & Tensile strength \\
\hline$f_{c e}$ & $1 / 3 f_{c p}$ & - & [MPa] & \multirow{6}{*}{$\begin{array}{c}\text { Compressive } \\
\text { hardening/softening } \\
\text { behavior }\end{array}$} \\
\hline$f_{c p}$ & 2.6 & - & [MPa] & \\
\hline$f_{c m}$ & $1 / 2 f_{c p}$ & - & [MPa] & \\
\hline$f_{c r}$ & $1 / 7 f_{c p}$ & - & [MPa] & \\
\hline$\kappa_{p} / e_{h}$ & 0.009 & - & {$[-]$} & \\
\hline$\kappa_{m} / e_{h}$ & 0.049 & - & {$[-]$} & \\
\hline$\Phi$ & 37 & 45 & {$\left[{ }^{\circ}\right]$} & Friction angle \\
\hline$\Psi$ & 45 & - & {$\left[{ }^{\circ}\right]$} & $\begin{array}{c}\text { Angle of the } \\
\text { linearized } \\
\text { compressive cap }\end{array}$ \\
\hline$G_{f}^{I}$ & 0.010 & 10 & {$[\mathrm{~N} / \mathrm{mm}]$} & $\begin{array}{l}\text { Mode I fracture } \\
\text { energy }\end{array}$ \\
\hline$G_{f}^{I I}$ & 0.0050 & 10 & {$[\mathrm{~N} / \mathrm{mm}]$} & $\begin{array}{l}\text { Mode II fracture } \\
\text { energy }\end{array}$ \\
\hline
\end{tabular}




\begin{tabular}{|c|c|c|c|}
\hline \multicolumn{4}{|c|}{ Masonry interfaces } \\
\hline$E$ & 7000 & [MPa] & Young Modulus \\
\hline$G$ & $\mathrm{E} / 2$ & [MPa] & Shear Modulus \\
\hline$C$ & $1.0 f_{t}$ & [MPa] & Cohesion \\
\hline$f_{t}$ & 0.1 & {$[\mathrm{MPa}]$} & Tensile strength \\
\hline$f_{c e}$ & $1 / 3 f_{c p}$ & [MPa] & \multirow{6}{*}{$\begin{array}{l}\text { Compressive } \\
\text { hardening/softening behavior }\end{array}$} \\
\hline$f_{c p}$ & 4 & {$[\mathrm{MPa}]$} & \\
\hline$f_{c m}$ & $1 / 2 f_{c p}$ & {$[\mathrm{MPa}]$} & \\
\hline$f_{c r}$ & $1 / 7 f_{c p}$ & {$[\mathrm{MPa}]$} & \\
\hline$\kappa_{p} / e_{h}$ & 0.009 & {$[-]$} & \\
\hline$\kappa_{m} / e_{h}$ & 0.049 & {$[-]$} & \\
\hline$\Phi$ & 37 & {$\left[{ }^{\circ}\right]$} & Friction angle \\
\hline$\Psi$ & 45 & {$\left[{ }^{\circ}\right]$} & $\begin{array}{l}\text { Angle of the linearized } \\
\text { compressive cap }\end{array}$ \\
\hline$G_{f}^{I}$ & 0.010 & {$[\mathrm{~N} / \mathrm{mm}]$} & Mode I fracture energy \\
\hline$G_{f}^{I I}$ & 0.0050 & {$[\mathrm{~N} / \mathrm{mm}]$} & Mode II fracture energy \\
\hline \multicolumn{4}{|c|}{ Backfill } \\
\hline$E$ & 1000 & [MPa] & Young Modulus \\
\hline$G$ & $\mathrm{E} / 2$ & [MPa] & Shear Modulus \\
\hline$C$ & $1.0 f_{t}$ & [MPa] & Cohesion \\
\hline$f_{t}$ & 0.05 & [MPa] & Tensile strength \\
\hline$f_{c e}$ & $1 / 3 f_{c p}$ & [MPa] & \multirow{6}{*}{$\begin{array}{c}\text { Compressive } \\
\text { hardening/softening behavior }\end{array}$} \\
\hline$f_{c p}$ & 2.0 & {$[\mathrm{MPa}]$} & \\
\hline$f_{c m}$ & $1 / 2 f_{c p}$ & [MPa] & \\
\hline$f_{c r}$ & $1 / 7 f_{c p}$ & {$[\mathrm{MPa}]$} & \\
\hline$\kappa_{p} / e_{h}$ & 0.009 & {$[-]$} & \\
\hline$\kappa_{m} / e_{h}$ & 0.049 & {$[-]$} & \\
\hline$\Phi$ & 37 & {$\left[{ }^{\circ}\right]$} & Friction angle \\
\hline$\Psi$ & 45 & {$\left[{ }^{\circ}\right]$} & $\begin{array}{l}\text { Angle of the linearized } \\
\text { compressive cap }\end{array}$ \\
\hline$G_{f}^{I}$ & 0.010 & {$[\mathrm{~N} / \mathrm{mm}]$} & Mode I fracture energy \\
\hline$G_{f}^{I I}$ & 0.0050 & {$[\mathrm{~N} / \mathrm{mm}]$} & Mode II fracture energy \\
\hline
\end{tabular}

